\title{
A mitochondrial electron transport chain with atypical subunit composition confers oxygen sensitivity to a mammalian chemoreceptor
}

\author{
Alba Timón-Gómez ${ }^{1 *}$, Alexandra L. Scharr ${ }^{2 *}$, Nicholas Y. Wong ${ }^{2 *}$, Erwin Ni², Arijit Roy ${ }^{3,4,5}$, Min \\ Liu $^{2}$, Julisia Chau², Jack L. Lampert², Homza Hireed², Noah S. Kim², Masood Jan², Alexander \\ R. Gupta ${ }^{6.7}$, Ryan W. Day ${ }^{6}$, James M. Gardner ${ }^{6,7}$, Richard J. A. Wilson ${ }^{3,4,5}$, Antoni Barrientos ${ }^{1 \dagger}$, \\ Andy J. Chang ${ }^{2 \dagger}$
}

*equal contribution

${ }^{\dagger}$ corresponding authors

Affiliations:

${ }^{1}$ Department of Neurology, University of Miami Miller School of Medicine, Miami, FL 33136, USA

${ }^{2}$ Department of Physiology and Cardiovascular Research Institute, University of California, San

Francisco, San Francisco, CA 94158, USA

${ }^{3}$ Department of Physiology and Pharmacology, University of Calgary, Calgary, Alberta, Canada.

${ }^{4}$ Hotchkiss Brain Institute, University of Calgary, Calgary, Alberta, Canada.

${ }^{5}$ Alberta Children's Hospital Research Institute, University of Calgary, Calgary, Alberta, Canada

${ }^{6}$ Department of Surgery, University of California, San Francisco, San Francisco, CA, 94143, USA.

${ }^{7}$ UCSF Diabetes Center, University of California, San Francisco, San Francisco, CA, 94143, USA. 


\section{Abstract}

The carotid body (CB) is the major chemoreceptor for blood oxygen in the control of ventilation in mammals, contributing to physiological adaptation to high altitude, pregnancy, and exercise, and its hyperactivity is linked to chronic conditions such as sleep-disorder breathing, hypertension, chronic heart failure, airway constriction, and metabolic syndrome (1-3). Upon acute hypoxia $\left(\mathrm{PO}_{2}=100 \mathrm{mmHg}\right.$ to $\left.<80 \mathrm{mmHg}\right), \mathrm{K}^{+}$channels on $\mathrm{CB}$ glomus cells are inhibited, causing membrane depolarization to trigger $\mathrm{Ca}^{+2}$ influx and neurotransmitter release that stimulates afferent nerves (1-3). A longstanding model proposes that the CB senses hypoxia through atypical mitochondrial electron transport chain (ETC) metabolism that is more sensitive to decreases in oxygen than other tissues. This model is supported by observations that ETC inhibition by pharmacology and gene knockout activates CB sensory activity and that smaller decreases in oxygen concentration inhibit ETC activity in CB cells compared to other cells (1-5). Determining the composition of atypical ETC subunits in the CB and their specific activities is essential to delineate molecular mechanisms underlying the mitochondrial hypothesis of oxygen sensing. Here, we identify HIGD1C, a novel hypoxia inducible gene domain factor isoform, as an ETC Complex IV (CIV) protein highly and selectively expressed in glomus cells that mediates acute oxygen sensing by the $\mathrm{CB}$. We demonstrate that HIGD1C negatively regulates oxygen consumption by CIV and acts with the hypoxia-induced CIV subunit COX4I2 to enhance the sensitivity of CIV to hypoxia, constituting an important component of mitochondrial oxygen sensing in the CB. Determining how HIGD1C and other atypical CIV proteins expressed in the CB work together to confer exquisite oxygen sensing to the ETC will help us better understand how tissue- and condition-specific CIV subunits contribute to physiological function and disease (6) and allow us to potentially target these proteins to treat chronic diseases characterized by CB dysfunction (7). 


\section{HIGD1C is a novel mitochondrial protein expressed in CB glomus cells}

Because the CB sensory activity correlates with changes in ETC activity (1-3), we sought to identify atypical mitochondrial proteins that may alter ETC responses to changes in oxygen availability. Using whole-genome expression data from RNAseq, we looked for genes encoding putative mitochondrial proteins that are overexpressed in the mouse CB compared to the adrenal medulla, a similar neuroendocrine tissue that is much less oxygen-sensitive than the CB in the adult (8). We found that three such genes, Higd1c, Cox4i2, and Ndufa4l2, were expressed at significantly higher levels in the mouse CB (Fig. 1a). By RT-qPCR, we observed similar upregulation of these genes in the human CB (Fig. 1b). In the mouse CB, Cox4i2, Ndufa412, and Cox8b were previously identified as genes upregulated by Hif2a, a hypoxiainducible transcription factor critical for CB development and function $(4,9)$. Of these genes, Cox4i2 and Ndufa4l2 were overexpressed in the CB versus the adrenal medulla (Fig. 1a). We focused this study on Higd1c, the most differentially expressed of these genes and one of the top ten most upregulated genes genome-wide in the mouse CB versus adrenal medulla (8).

Higd1c is a novel member of the HIG1 hypoxia inducible domain gene family that also includes Higd1a, Higd1b, and Higd2a. Higd1a and Higd2a, the mammalian orthologs of the yeast respiratory supercomplex factors 1 and 2 (Rcf1 and Rcf2), encode mitochondrial proteins that promote the biogenesis of ETC complexes and their assembly into supercomplexes (10). To determine the subcellular localization of HIGD1C, we overexpressed FLAG-tagged HIGD1C in HEK293T cells and observed that it co-localizes with the mitochondrial marker HSP60, suggesting that HIGD1C is targeted to mitochondria like HIGD1A and HIGD2A (Fig. 1c).

Higd1a and Higd2a are expressed in many mouse and human tissues and at much higher levels than Higd1c $(11,12)$. The ENCODE project reports very low expression of Higd1c in mouse tissues, except in the kidney (13). We found that Higd1c is expressed at high levels in the CB compared to other tissues in the mouse (Fig. S1a, Fig. S2a-d). Within the CB, glomus cells sense hypoxia to stimulate afferent nerves to increase ventilation (14). mRNA for Higd1c 
was localized in the same cells as mRNA for Th, a marker of glomus cells (Fig. 1d, e, Fig. S3aI), agreeing with single-cell RNAseq findings (15) (Fig. S2e). As a positive control, we confirmed the previously reported expression of Higd1c in kidney proximal tubules (16) (Fig. S4a-m). These results indicate that Higd1c is expressed in a key cell population for oxygen sensing in the $\mathrm{CB}$.

To determine if HIGD1C plays a role in CB sensory signaling, we generated mutants in Higd1c by CRISPR/Cas9 in C57BL/6J mice. We isolated mutants that carried large deletions that span upstream sequences through the first coding exon and small indels in the first coding exon (Fig. S1a-c). We characterized one allele representing each class of mutation (3-1, 1-1, and 5-3) that either prevent mRNA production or alter the protein sequence and cause premature stops (Fig. S1d). For all three alleles, heterozygous mutants were fertile, and homozygous mutants were viable and not underrepresented in the progeny (Table S1).

For the large deletion allele 3-1, RT-qPCR using primers that target Higd1c mRNA sequences deleted in this strain amplified $\sim 100$-fold less product from mRNA from Higd1c ${ }^{-/}$CBs and kidneys as expected (Fig. 1f, Fig. S2a-d, Fig. S4q), confirming the specificity of this primer set. Similarly, the loss of Higd1c in situ hybridization signal in CBs and kidneys from Higd1c 3$1^{-/-}$mutants validated the specificity of probes for Higd1c exons 1 and 2 (Fig. S3m-o, Fig. S4np). In 1-1 and 5-3 alleles that carry mutations in exon 3, Higd1c mRNA levels were reduced in CBs and kidneys from Higd1c $c^{-/}$mutants compared to Higd1 $c^{+/+}$animals (Fig. 1f, Fig. S4q). From these results, we infer that Higd1c 3-1, 1-1, and 5-3 alleles all reduce HIGD1C activity.

\section{HIGD1C mediates CB sensory and metabolic responses to hypoxia}

To assess if HIGD1C plays a role in CB oxygen sensing at the whole animal level, we performed whole-body plethysmography on awake, unanesthetized mice. A decrease in arterial blood oxygen stimulates the $C B$ to signal to the brainstem to increase ventilation within seconds (1-3). Higd1 $c^{-/-}$mutants of all three alleles had normal ventilation in normoxia but were defective 
in the hypoxic ventilatory response (Fig. 2a-d, Fig. S5a-h). By contrast, Higd1c ${ }^{-/}$mutants had robust ventilatory responses to hypercapnia comparable to Higd1c ${ }^{+/+}$animals (Fig. 2e-h, Fig. S5i-p). Because the CB is the major chemoreceptor for oxygen but only a minor contributor to $\mathrm{CO}_{2} / \mathrm{H}^{+}$sensing in the control of ventilation (14), these results suggest that Higd1c specifically regulates ventilatory responses to hypoxia. The reduction in hypoxic ventilatory response in Higd1c mutants is most likely due to defects in the CB because Higd1c was expressed at low levels in the petrosal ganglion and brainstem downstream of the CB in the neuronal circuit (Fig. $\mathrm{S} 2 \mathrm{a}, \mathrm{b})$.

Loss of function mutations in the ETC CIl succinate dehydrogenase D subunit (Sdhd) and the transcriptional factor Hif2a that regulates the expression of multiple ETC subunits cause loss of CB glomus cells during development $(4,9,17)$. The number of TH-positive glomus cells in CBs from Higd1 $\mathrm{c}^{+/+}$and Higd1 $\mathrm{c}^{-/}$animals was not significantly different for all three alleles (Fig. 1g-i), and there were no gross morphological abnormalities in mutant CBs. Thus, it is unlikely that the hypoxic ventilatory response defect observed in Higd1 $1 \mathrm{c}^{-/}$mutants is due to the loss of glomus cells.

We next examined the integrated sensory output from the CB at the level of the carotid sinus nerve (CSN), a branch of the glossopharyngeal nerve that connects the CB to the brainstem. When the $\mathrm{CB}$ is activated, glomus cells release neurotransmitters to stimulate the CSN to transduce signals to the brainstem (14). Baseline CSN activity was similar between Higd1c $1-1^{+/+}$and Higd1c 1-1/\% tissue (Fig. 3a). As oxygen levels were decreased, CSN activity increased in a dose-dependent manner in Higd1c 1-1 ${ }^{+/+}$tissue (Fig. 3b, Fig. S6a). However, this response to hypoxia was significantly attenuated in CSNs from Higd1c $1-1^{-/}$mutants, while the response to high $\mathrm{CO}_{2} / \mathrm{H}^{+}$was unaffected (Fig. 3b, Fig. S6b). Thus, we conclude that HIGD1C specifically mediates oxygen sensing at the whole organ level.

Because Higd1c is expressed in glomus cells (Fig. 1c, d), we evaluated if Higd1c mutants are also defective in the sensory responses of these oxygen-sensitive cells. Glomus 
cells exhibit acute calcium transients in response to stimuli, which can be visualized by the genetically encoded calcium indicator GCaMP3 (8). We found that glomus cells from Higd1c 1$1^{-/-}$mutants mounted a weaker calcium response to hypoxia than those from Higd1c $1-1^{+/+}$ animals, with fewer glomus cells responding strongly to both levels of hypoxia (Fig. 3c, d, Fig. S6c-h). In contrast to hypoxia, glomus cells from Higd1c 1-1/- mutants were not significantly different in their calcium response to low $\mathrm{pH}$ or high $\mathrm{KCl}$ compared to glomus cells from Higd1c $1-1^{-/}$animals (Fig. 3d-e, Fig. S6c, d). Low pH and high $\mathrm{KCl}$ modulate the activity of $\mathrm{K}^{+}$channels on the plasma membrane of glomus cells thought to act downstream of mitochondria in CB oxygen sensing $(18,19)$. Calcium responses to cyanide, a potent ETC CIV inhibitor, were

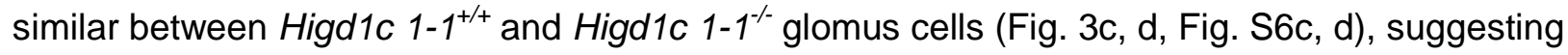
that strong ETC inhibition can still trigger sensory responses in Higd1c 1-1/- glomus cells like other mutants with defects in CB oxygen sensing $(20,21)$. Together, these results show that HIGD1C contributes specifically to glomus cell responses to hypoxia involved in oxygen sensing.

To determine if HIGD1C modulates oxygen sensitivity of mitochondria in glomus cells, we used rhodamine 123 (Rh123) to image CB inner mitochondrial membrane (IMM) potential generated by ETC activity. In normoxia and hyperoxia, Rh123 readily moves to the mitochondrial matrix, where it is quenched by self-aggregation. Hypoxia inhibits ETC activity, leading to a decrease in IMM potential and an increase in Rh123 fluorescence as the dye moves out of the mitochondrial matrix and disaggregates (22). Higd1c 1-1\% glomus cells had an attenuated response to hypoxia and a greater percentage of cells that responded poorly to FCCP, a potent uncoupler of oxidative phosphorylation that depolarizes the IMM (Fig. 4a, b). If we only compared glomus cells that had strong FCCP response $>0.2$, we found that Rh123 fluorescence was greater in Higd1c 1-1\% glomus cells in normoxia $\left(\mathrm{PO}_{2}=100 \mathrm{mmHg}\right)$, suggesting that the ETC was less active in polarizing the IMM. Nevertheless, the increase in fluorescence in hypoxia $\left(\mathrm{PO}_{2}<80 \mathrm{mmHg}\right.$ ) was smaller than in Higd1c 1-1 ${ }^{+/+}$glomus cells (Fig. 
4c, d, Fig. S7a-c). This pattern of IMM potential from normoxia to hypoxia resembles that of acute CII inhibition on CB sensory activity (23). As a control for hypoxic stimulus delivery, we found that vascular cells, which are less oxygen-sensitive than glomus cells, had a left-shifted IMM potential response to hypoxia as expected (Fig. S7d-f). These results demonstrate that HIGD1C enhances ETC inhibition by hypoxia in glomus cells, a response linked to CB sensory activity (1-3).

\section{HIGD1C associates with and regulates ETC Complex IV activity}

To assess the role of HIGD1C in ETC function, we overexpressed FLAG-tagged human or mouse HIGD1C in HEK293T cells to perform biochemical and metabolic studies of mitochondria. In wild-type HEK293T cells, HIGD1C mRNA was expressed at very low levels $\left(3 \times 10^{-6}\right.$ the level of GAPDH by RT-qPCR). Overexpressed FLAG-tagged HIGD1C associated with ETC CIV and cytochrome $c$ (Fig. S8a-c). Notably, HIGD1C overexpression severely reduced the abundance of ETC supercomplexes, and supercomplexes that did assemble contained only traces of in-gel CIV activity (Fig. S8d, e). These defects in supercomplex formation correlated with a decrease in CIV enzymatic activity (Fig. S8f, g) and oxygen consumption rate (Fig. S8h, i).

Because HIGD1C is most similar to HIGD1A and HIGD2A, we overexpressed HIGD1C in HIGD1A-KO and HIGD2A-KO HEK293T cell lines to determine if it could rescue ETC defects of these KO cell lines (24). As in wild-type cells, HIGD1C associated with CIV and cytochrome c in HIGD1A-KO and HIGD2A-KO mutant cells (Fig. 5a, b, Fig. S9a-c, Fig. S10a-d). Unlike overexpression of HIGD1A, HIGD1C could not rescue defects in the assembly of supercomplexes in either HIGD1A-KO or HIGD2A-KO cells (Fig. 5c, Fig. S9d, Fig. S10e). Strikingly, however, HIGD1C overexpression restored CIV activity in HIGD1A-KO, but not HIGD2A-KO cells (Fig. 5d, Fig. S9e, f, Fig. S10f). This could be due to non-overlapping activities of HIGD1C and HIGD2A and/or more severe defects in CIV assembly in HIGD2A-KO 
cells (Fig. S9d). Instead of acting as a CIV assembly factor as HIGD2A, HIGD1C could play a regulatory role in modulating CIV activity like HIGD1A (24). In agreement, at the overall ETC level, cellular respiration was also restored by HIGD1C overexpression in HIGD1A-KO cells (Fig. S10g, h). Overexpression of mouse HIGD1C induced a weaker rescue of CIV activity than human HIGD1C, likely due to disruption of species-specific associations with ETC subunits (Fig. 5, Fig. S10f). Nonetheless, mouse HIGD1C fully rescued mitochondrial oxygen consumption due to the spare respiratory capacity of the ETC (Fig. S10g, h). These rescue experiments show that HIGD1C is not involved in ETC complex or supercomplex biogenesis, but, similarly to HIGD1A, it can interact with CIV to regulate its activity.

HIGD1C could modulate CIV activity by (1) mediating the formation of an electrontransfer bridge between ETC CIII and IV and/or (2) by producing a structural change around the active center of the enzyme. The former possibility is unlikely because overexpression of HIGD1C in HIGD1A-KO cells did not increase the levels of cytochrome $c$ present in ETC supercomplexes (Fig. S10e) compared to control cell lines. The CIV active center is located in subunit 1 (COX1) and formed by a binuclear heme-copper center (heme $a_{3}-\mathrm{Cu}_{\mathrm{B}}$ ). During catalysis, reduced cytochrome $c$ delivers electrons to CIV subunit 2 copper site $\left(\mathrm{COX} 2-\mathrm{Cu}_{\mathrm{A}}\right)$, which are then transferred to the heme a center in COX1, and subsequently to the active site where oxygen binds and is reduced to water (25). To analyze the protein environment surrounding the CIV active center, we measured UV/Vis absorption spectra of total cytochromes extracted from purified mitochondria. The absence of HIGD1A produced a blue shift in the peak of heme a+a3 absorbance from $603 \mathrm{~nm}$ to $599 \mathrm{~nm}$ (Fig. 5e, Fig. S11a-d) that is associated with changes in the environment around the CIV heme a centers (26). Notably, previous studies showed a similar alteration of the CIV heme a environment in the presence of excess recombinant HIGD1A (27). This spectral shift observed in the KO cell line was completely restored by the expression of HIGD1A. While the wavelength at the peak appeared to be restored by overexpression of human HIGD1C (Fig. S11a), expression of human or mouse 
HIGD1C generated a broader peak, probably due to the existence of a mixed population of the enzyme (Fig. S11e), only partially restoring the spectral shift. A blue shift in the wavelength at the peak was apparent in HIGD1A-KO cells overexpressing human HIGD1C and COX4I2 together or mouse HIGD1C alone, suggesting that COX4I2 can further modify the effect of HIGD1C overexpression. These results suggest that interaction of HIGD1C with CIV can alter the active site and activity of CIV and are consistent with observations that acute hypoxia shifts the absorbance spectra of cytochromes in the CB (1-3).

\section{HIGD1C and COX4I2 enhance the sensitivity of ETC Complex IV to hypoxia}

Previous studies describe the exquisite sensitivity of mitochondria of CB glomus cells to hypoxia (1-3). To determine if HIGD1C can alter the sensitivity of ETC to hypoxia, we measured cellular respiration of HIGD1A-KO cells overexpressing HIGD1C. In this cell line, the pattern of HIGD protein expression mimicked that found in mouse and human CBs, where Higd1c and Higd2a are expressed at high levels and Higd1a at levels undetectable by singlecell RNAseq (15) (Fig. S2e, f). Using an artificial electron donor system to isolate cytochrome cCIV activity, we measured oxygen consumption of HIGD1A-KO cell lines overexpressing atypical mitochondrial subunits found in glomus cells in normoxia and hypoxia by high-resolution respirometry. Co-overexpression of HIGD1C and COX4I2 in HIGD1A-KO cells, which better models the ETC composition in CB glomus cells (Fig. S2e, f), decreased CIV-dependent respiration in hypoxia more than wild-type and other cell lines, including the one overexpressing HIGD1C alone, revealing an enhanced response to hypoxia (Fig. 5f, g). Overexpression of COX4I2 in HEK293T cells increased CIV-dependent respiration in both normoxic and hypoxic conditions, probably due to an increase in CIV abundance (Fig. S10i), but the ratio between conditions remained unaltered compared to the other cell lines. These results demonstrate that co-overexpression of HIGD1C and COX4I2, two atypical mitochondrial ETC proteins expressed in CB glomus cells, can confer oxygen sensitivity to HEK293T cells that are not ordinarily 
responsive to mild levels of hypoxia. Therefore, the COX4I2-containing ETC CIV, and its regulation by HIGD1C, emerge as the necessary and sufficient factors driving oxygen sensitivity in $\mathrm{CB}$ glomus cells.

\section{Discussion}

A role for the mitochondrial ETC in CB oxygen sensing dates back to Corneille Heymans's experiments in the 1930's showing CB stimulation by the CIV inhibitor CN. Subsequent measurements of NADH and IMM potential in CB glomus cells at different oxygen levels demonstrate the exquisite sensitivity of their ETC to hypoxia (1-3). Previous studies found that mouse knockouts in specific $\mathrm{Cl}$ and CIV subunits exhibit defects in CB sensory and metabolic responses to hypoxia $(4,5)$, phenocopying the effect of drugs that inhibit these ETC complexes. However, it is not clear whether the phenotype observed in these mutants is due to the unique oxygen sensitivity of these subunits or their essential roles in Cl and CIV function.

Using whole-genome transcriptomics, we identified HIGD1C as a novel mitochondrial CIV protein essential for oxygen sensitivity of the CB. We found that HIGD1C interacts with CIV and alters the conformation of its enzymatic active center. In the absence of HIGD1A, HIGD1C and COX4I2 overexpression increased oxygen sensitivity of CIV in HEK293T cells, and overexpression of COX4I2 increased the stability of HIGD1C (Fig. S10b). Since COX4I1, the ubiquitously expressed COX4 subunit, associates with HIGD1A in CIV assembly (24), the alternative COX4I2 subunit may assemble with HIGD1C. In opposition to its effect in HIGD1AKO cells, COX4I2 overexpression in the presence of HIGD1A in WT cells decreases HIGD1C abundance, suggesting that HIGD1A and HIGD1C interact with CIV in the same domains (Fig. S8a).

While we demonstrate here that HIGD1C and COX4I2 are sufficient to confer detectable oxygen sensitivity to CIV in HEK293T cells, additional components will be required to reconstitute the oxygen sensitivity of $\mathrm{CB}$ glomus cells. Other proteins upregulated in $\mathrm{CB}$ glomus 
cells, such as the CIV subunits NDUFA4L2 and COX8B and the glycolytic enzyme PCX $(4,8)$, are attractive candidates for further study to elucidate their potential contribution to the CB molecular mechanism(s) of oxygen sensing.

There is growing appreciation that CIV contains subunits that are tissue-specific and/or regulated by development, physiological changes (hypoxia and low glucose), and diseases (cancer, ischemia/reperfusion injury, and sepsis) $(6,10)$. In addition to the CB, HIGD1C is expressed in kidney proximal tubules (16) (Fig. S4a-m). Compared to other nephron segments, the proximal tubules have the highest oxygen demand, exhibit greater ETC sensitivity to hypoxia, and are most susceptible to ischemia/reperfusion injury (28). We speculate that HIGD1C modulates ETC activity in multiple oxygen-sensitive cell types to match oxygen utilization to physiological function. 


\section{Materials and Methods}

\section{Animals}

All experiments with animals were approved by the Institutional Animal Care and Use Committees at the University of California, San Francisco, and the University of Calgary. C57BL/6J (JAX) was used as the wild-type strain. Other mouse strains obtained from repositories were Th-Cre driver: B6.FVB(Cg)-Tg(Th-cre) $)^{\text {Fl172Gsat } / M m u c d ~(M M R R C) ~(29) ~ a n d ~}$ ROSA-GCaMP3: B6;129S-Gt(ROSA)26Sor ${ }^{\text {tm38(CAG-GCaMP3)Hze }} / J$ (JAX) (30). Adult animals of both sexes from multiple litters were used in all experiments.

Higd1c mutants were generated by injecting C57BL/6J embryos with in vitro transcribed sgRNA-1 and sgRNA-2 (10 ng $\mu^{-1}$ each) together with Cas9 mRNA (50 ng $\left.\mu^{-1}\right)$ and transferring injected embryos to pseudo-pregnant CD-1 females. Six founders were born and bred to C57BL/6J animals to isolate individual mutations transmitted through the germline, and sequences around sgRNA targets were PCR amplified and sequenced to identify mutations (Fig. S1). Higd1c mutant lines were maintained by breeding Higd1c $c^{+/}$animals to each other.

\section{RNA purification and RT-qPCR}

For mouse CB and kidney tissue, animals were anaesthetized with isoflurane and decapitated, and tissues were dissected immediately. For all other tissues, animals were anesthetized and exsanguinated by perfusing PBS through the heart before decapitation and dissection. For human tissue, CB bifurcations were procured from research-consented, deidentified organ transplant donors through a collaboration with the UCSF VITAL Core (https://surgeryresearch.ucsf.edu/laboratories-research-centers/vital-core.aspx) -- UCSF IRBdesignated as non-human subjects research specimens -- and were stored and transported in Belzer UW Cold Storage Solution (Bridge to Life) on ice. CBs were then dissected in UW Solution within $18 \mathrm{~h}$ after harvest. After dissection, tissues were transferred to RNAlater 
solution (Qiagen) and stored at $4{ }^{\circ} \mathrm{C}$. For CB, kidney, adrenal gland, and all neuronal tissues, tissue pieces were disrupted and homogenized in a guanidine-isothiocyanate lysis buffer (Buffer RLT, Qiagen) using a glass tissue grinder (Corning), followed by a 23 gauge needle and syringe, and purified by silica-membrane columns using the RNeasy Micro Kit (Qiagen). For heart, liver, lung, and spleen, tissue pieces were ground using a glass tissue grinders (Corning) in TRIzol (Ambion), and RNA was purified by acid guandinium thiocyanate-phenol-chloroform extraction followed by isopropanol precipitation. For cell culture, cells were pelleted and resuspended in Buffer RLT before RNA purification using columns. RNA quality was assessed by visualizing $28 \mathrm{~S}$ and $18 \mathrm{~S}$ rRNA by agarose gel electrophoresis, and RNA concentration was measured with a Nanodrop ND-1000 Spectrophotometer (Thermo). RNA was stored at $-80{ }^{\circ} \mathrm{C}$.

Two-step RT-qPCR was performed. First, purified total RNA was synthesized into cDNA:RNA hybrids with Maxima H Minus Reverse Transcriptase (Thermo) and primed using equal amounts of oligo(dT)15 primers (Promega) and random hexamers (Thermo). RNasin Plus RNase Inhibitor (Promega) was also added to the mixture. Next, qPCR was performed using PowerUp SYBR Green Master Mix (Applied Biosystems), at $10 \mu \mathrm{l}$ reaction volume, following manufacturer instructions. Three technical replicates were performed for each reaction and plated in TempPlate 384-well PCR plates (USA Scientific). Sample plates were run using a QuantStudio 5 Real-Time PCR System (Applied Biosystems) using a 40-cycle amplification protocol.

QuantStudio software was used to calculate threshold cycle (Ct) values. Undetermined Ct values were set to $\mathrm{Ct}=40$. Ct values were averaged for all technical replicates, and normalized to either Actb or to $G A P D H$, using the $\triangle \mathrm{Ct}$ method.

\section{Cell Culture}

HIGD1A-KO and HIGD2A-KO cells were constructed in HEK293T using the TALEN technology as described in (24). HEK293T cells were grown in 25 mM glucose Dulbecco's 
modified Eagle's medium (DMEM, Life Technologies) supplemented with $10 \%$ fetal bovine serum (FBS), $2 \mathrm{mM} \mathrm{L-glutamine,} 1 \mathrm{mM}$ sodium pyruvate, and $50 \mu \mathrm{g} \mathrm{m} \mathrm{l}^{-1}$ uridine without antibiotics, at $37^{\circ} \mathrm{C}$ under $5 \% \mathrm{CO}_{2}$. For metabolic imaging involving HEK293T cells, $10 \mathrm{~mm}$ glass coverslips were placed into $1.96 \mathrm{~cm}^{2}$ wells, and coated with $0.2 \mathrm{mg} \mathrm{ml}^{-1}$ poly-D-lysine for at least two hours at RT. Two days prior to the experiment, $7.5 \times 10^{4}$ cells in $500 \mu \mathrm{l}$ of cell media were then seeded into each well. For hypoxia experiments, cell cultures were exposed to $1 \% \mathrm{O}_{2}$ for up to $24 \mathrm{~h}$, or as controls, to standard cell culture oxygen tension $\left(18.6 \% \mathrm{O}_{2}\right)$. Experiments under controlled oxygen tensions were performed in a HypOxystation ${ }^{\circledR} \mathrm{H} 35$ (HypOxygen) to minimize undesired oxygen reperfusion. Routinely, cells were analyzed for mycoplasma contamination.

\section{Plasmid generation and transfection}

HIGD1C-Myc-DDK/FLAG constructs in pCMV6-Entry were cloned under the control of a CMV promoter in the pCMV6-A-Entry-Hygro plasmid, and COX4I1/COX4I2-Myc-DDK constructs in pCMV6-Entry were cloned in the pCMV6-A-Entry-BSD, using Sfg1 and Pme1 sites. 1-2 $\mu \mathrm{g}$ of vector DNA was mixed with $5 \mu \mathrm{l}$ of Lipofectamine ${ }^{\mathrm{TM}}$ (Thermo Fisher) in OPTIMEM-I media (GIBCO) to transfect $1.5 \times 10^{6}$ cells according to manufacturer's instructions. After $48 \mathrm{~h}$, media was supplemented with $200 \mu \mathrm{g} \mathrm{ml}^{-1}$ of hygromycin or $10 \mu \mathrm{g} \mathrm{ml}^{-1}$ of blasticidin and maintained for at least 21 days.

\section{In situ hybridization}

Animals were anesthetized with isoflurane, decapitated, and dissected. Tissue was fixed in RNase-free $4 \%$ PFA/PBS overnight at $4{ }^{\circ} \mathrm{C}$ and equilibrated serially in $10 \%$ sucrose/PBS for $>1 \mathrm{~h}, 20 \%$ sucrose/PBS for $>2 \mathrm{~h}$, and $30 \%$ sucrose/PBS overnight, all at $4{ }^{\circ} \mathrm{C}$. Tissue was then embedded in O.C.T. (TissueTek) and stored at $-80^{\circ} \mathrm{C}$. The tissue was sectioned at $10 \mu \mathrm{m}$ using a Leica CM3050S cryostat and stored in $-80{ }^{\circ} \mathrm{C}$. 
Following the BaseScope protocol for fixed frozen sections, slides were baked for 50 min at $60^{\circ} \mathrm{C}$ and post-fixed with $10 \%$ neural-buffered saline for $15 \mathrm{~min}$ at $60^{\circ} \mathrm{C}$. This was followed by target retrieval for $5 \mathrm{~min}$ at $100^{\circ} \mathrm{C}$ and protease III treatment for $30 \mathrm{~min}$ at $40^{\circ} \mathrm{C}$. Using the BaseScope Duplex Detection Reagent kit (Advanced Cell Diagnostics, 323810), subsequent steps of hybridization and detection followed the vendor's protocol. Probes are listed in Table S2. The probe set for Higd1c was custom-designed to target only the first two exons of Higd1c. For detection of Th mRNA, amplification steps 7 and 8 were reduced from $30 \mathrm{~min}$ and $15 \mathrm{~min}$, respectively, to $15 \mathrm{~min}$ and $7.5 \mathrm{~min}$ for some samples. Images were collected on a Nikon $\mathrm{Ti}$ widefield inverted microscope using a DS-Ri2 color camera.

\section{Immunostaining}

Cultured cells on coverslips were fixed with $1 \%$ or $4 \%$ PFA/PBS for 10 min at $22{ }^{\circ} \mathrm{C}$ and used immediately or stored in PBS at $4{ }^{\circ} \mathrm{C}$. The tissue was fixed in $4 \%$ PFA/PBS for 10 min at $22{ }^{\circ} \mathrm{C}$ and equilibrated in $30 \%$ sucrose overnight at $4^{\circ} \mathrm{C}$. Tissue was embedded in O.C.T. (TissueTek) and stored at $-80^{\circ} \mathrm{C}$. Sections were cut at $10 \mu \mathrm{m}$ using a Leica CM3050S cryostat and stored in $-80^{\circ} \mathrm{C}$. Fixed cells or tissue sections were incubated with primary antibodies overnight at $4^{\circ} \mathrm{C}$. Primary antibodies were mouse anti-DDK/FLAG, mouse anti-HSP60, rabbit anti-TH, and rat anti-CD31, all used at 1:500. For kidney sections, fluorescein-labeled Lotus tetragonolobus lectin (LTL) was added during the primary antibody treatment. Incubation with secondary antibodies (1:250) conjugated to either Alexa Fluor 488, Alexa Fluor 555 (Life Technologies) or Cy3 (Jackson ImmunoResearch) was $45 \mathrm{~min}$ at $22{ }^{\circ} \mathrm{C}$. Samples were then incubated with DAPI (1 $\mathrm{ng} \mathrm{ml}^{-1}$, Life Technologies) for $5 \mathrm{~min}$ at $22{ }^{\circ} \mathrm{C}$ and mounted in Mowiol 488 (Polysciences) with DABCO (25 mg ml${ }^{-1}$, Sigma-Aldrich). Samples were imaged using a Leica SPE confocal microscope for cell culture and a Zeiss Axio Observer D1 widefield inverted microscope for tissue sections. 


\section{Whole-body plethysmography}

Adult mice were removed from the housing room and placed in the procedure room for a minimum of $1 \mathrm{~h}$ before starting the experiment to acclimate. Ventilation of unanesthetized, awake mice was measured using a commercial system for whole-body plethysmography (Scireq). Chamber pressure was detected by a pressure transducer and temperature and humidity by a sensor. These signals were integrated using IOX2 software (Scireq) to calculate the instantaneous flow rate. Baseline breathing was established during a period of at least 30 min in control gas. The baseline was followed by two hypoxic periods and one hypercapnic period, each lasting $5 \mathrm{~min}$, interspersed with recovery periods of $10 \mathrm{~min}$ in control gas. Gas mixtures for control, hypoxia, and hypercapnia were $21 \% \mathrm{O}_{2} / 79 \% \mathrm{~N}_{2}, 10 \% \mathrm{O}_{2} / 90 \% \mathrm{~N}_{2}$, and $5 \%$ $\mathrm{CO}_{2} / 21 \% \mathrm{O}_{2} / 79 \% \mathrm{~N}_{2}$, respectively (Airgas). The flow rate was held constant at $1.5 \mathrm{~L} / \mathrm{min}$.

Breathing traces were collected, and ventilatory parameters were calculated by IOX2 software (Scireq). Breath inclusion criteria were set in the software to the following: (1) inspiratory time (0.07-1 s), (2) expiratory time (0.1-1 s), (3) tidal volume (0.05-0.8 ml), and (4) respiratory rate (10-320 breaths per $\mathrm{min})$. Data for all accepted breaths were exported and processed using a custom $\mathrm{R}$ script to calculate the average respiratory rate, tidal volume, and minute ventilation for each period. Trials were rejected if many accepted breaths occurred during periods of animal sniffing, grooming, or movement. If a trial was rejected, the animal was retested on subsequent days, for up to four trials, until stable ventilation was reached in control periods.

\section{Carotid sinus nerve recordings}

Animals were heavily anesthetized with isoflurane and then decapitated (lower cervical level). The carotid bifurcation, including the $\mathrm{CB}$, carotid sinus nerve (CSN), and superior cervical ganglion, was quickly isolated en bloc for in vitro perfusion as described previously (31). The carotid bifurcation was then transferred to a dissection dish containing physiological saline 
(115 mM NaCl, $4 \mathrm{mM} \mathrm{KCl,} 24 \mathrm{mM} \mathrm{NaHCO}_{3}, 2 \mathrm{mM} \mathrm{CaCl}_{2}, 1.25 \mathrm{mM} \mathrm{NaH}_{2} \mathrm{PO}_{4}, 1 \mathrm{mM} \mathrm{MgSO}$, 10 $\mathrm{mM}$ glucose, $12 \mathrm{mM}$ sucrose) bubbling $95 \% \mathrm{O}_{2} / 5 \% \mathrm{CO}_{2}$. After $15-20 \mathrm{~min}$, the isolated tissue was transferred to a recording chamber (AR; custom made) with a built-in water-fed heating circuit, and the common carotid artery was immediately cannulated for luminal perfusion with

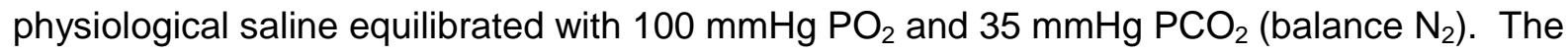
CSN was then carefully desheathed, and the carotid sinus region was bisected. The occipital and internal and external carotid arteries were ligated, and small incisions were made on the internal and external carotid arteries to allow perfusate to exit. A peristaltic pump was used to set the perfusion rate at $7 \mathrm{ml} \mathrm{min}^{-1}$, which was sufficient to maintain a constant pressure of 90$100 \mathrm{mmHg}$ at the tip of the cannula (AR, custom made). The perfusate was equilibrated with computer-controlled gas mixtures using $\mathrm{CO}_{2}$ and $\mathrm{O}_{2}$ gas analyzers (CA-2A and PA1B, Sable Systems); a gas mixture of $100 \mathrm{mmHg} \mathrm{PO}_{2}$ and $35 \mathrm{mmHg} \mathrm{PCO}_{2}$ (balance $\mathrm{N}_{2}$ ) was used to start the experiments (yielding $\mathrm{pH} \sim 7.4$ ). Before reaching the cannula, the perfusate was passed through a bubble trap and heat exchanger. The temperature of the perfusate, measured continuously as it departed the preparation, was maintained at $37 \pm 0.5^{\circ} \mathrm{C}$. The effluent from the chamber was recirculated.

Chemosensory discharge was recorded extracellularly from the whole desheathed CSN, which was placed on a platinum electrode and lifted into a thin film of paraffin oil. A reference electrode was placed close to the bifurcation. CSN activity was monitored using a differential AC amplifier (Model 1700, A-M Systems) and a secondary amplifier (Model 440, Brownlee Precision). The neural activity was amplified, filtered $(0.3-1 \mathrm{kHz})$, displayed on an oscilloscope, rectified, integrated (200 ms time constant), and stored on a computer using an analog-to-digital board (Digidata 1322A, Axon Instruments) and data acquisition software (Axoscope 9.0). Preparations were exposed to a brief hypoxic challenge $\left(\mathrm{PO}_{2}=60 \square \mathrm{mmHg}\right)$ to determine viability; preparations that failed to show a clear increase in activity during this challenge were discarded. 
After this challenge, the preparations were left undisturbed for $30 \square \mathrm{min}$ to stabilize before the experimental protocol was initiated.

The following protocol was used for all experiments: (1) the CB was perfused for 5 min with normoxia (100 mmHg $\mathrm{PO}_{2} / 35 \mathrm{mmHg}^{\mathrm{mCO}}$ ) to determine baseline CSN activity; (2) neural responses were obtained by challenging the carotid body for 4 min with mild, moderate, and severe hypoxia (80, 60 and $40 \mathrm{mmHg} \mathrm{PO}_{2}$, respectively) interspersed with normoxia; (3) a hypercapnic (60 mmHg $\mathrm{PCO}_{2}$ ) challenge was given for 4 min (Fig. S6a, b).

Data were analyzed offline using custom software (written by RJAW). CSN activity was divided into $60 \mathrm{~s}$ time bins, and the activity in each bin was rectified and summed (expressed as integrated neural discharge). The neural responses for different conditions in the protocol were normalized to the baseline (normoxic) condition. Data acquisition and CSN activity analysis were performed blinded to genotype.

\section{Calcium imaging}

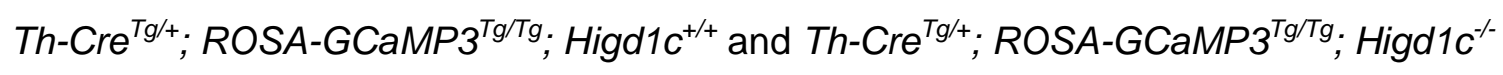

animals expressing GCaMP3 in glomus cells were generated, and CB was imaged as previously described (8). Animals were anesthetized with isoflurane and decapitated. Carotid bifurcations were dissected and cleaned in PBS to keep only the CB attached to the bifurcation. The preparation was then incubated in a physiological buffer $(115 \mathrm{mM} \mathrm{NaCl}, 5 \mathrm{mM} \mathrm{KCl}, 24 \mathrm{mM}$ $\mathrm{NaHCO}_{3}, 2 \mathrm{mM} \mathrm{CaCl}_{2}, 1 \mathrm{mM} \mathrm{MgCl}_{2}, 11 \mathrm{mM}$ glucose) at $26^{\circ} \mathrm{C}$ in a tissue culture incubator with $5 \% \mathrm{CO}_{2}$ before transfer to the recording chamber for imaging.

At baseline, the CB was superfused by gravity at $5 \mathrm{ml} \mathrm{min}^{-1}$ with physiological buffer bubbling $95 \% \mathrm{O}_{2} / 5 \% \mathrm{CO}_{2}$ in the reservoir to maintain $\mathrm{PO}_{2} \sim 700 \mathrm{mmHg}$ and $\mathrm{pH} 7.4$ in the imaging chamber at $22{ }^{\circ} \mathrm{C}$. Buffer $\mathrm{pH}$ was lowered to 6.8 by reducing $\mathrm{NaHCO}_{3}$ to $7 \mathrm{mM}$ with equimolar substitution of $\mathrm{NaCl}$ while bubbling $95 \% \mathrm{O}_{2} / 5 \% \mathrm{CO}_{2}$. Two levels of hypoxia at $\mathrm{PO}_{2} \sim 25 \mathrm{mmHg}$ and $50 \mathrm{mmHg}$ were generated by bubbling physiological buffer in the reservoir 
with $90 \% \mathrm{~N}_{2} / 5 \% \mathrm{O}_{2} / 5 \% \mathrm{CO}_{2}$ and $95 \% \mathrm{~N}_{2} / 5 \% \mathrm{CO}_{2}$, respectively. The preparation was sequentially stimulated with low $\mathrm{pH}$ and hypoxia for periods of $4.5 \mathrm{~min}$ each, with $3 \mathrm{~min}$ of recovery between stimuli. These were followed by $\mathrm{KCl}(40 \mathrm{mM})$ and $\mathrm{CN}(1 \mathrm{mM})$ for periods of 2.25 min each, with 4.5 min of recovery between stimuli (Fig. S6c, d).

Imaging was performed on a Zeiss LSM 7 MP two-photon microscope with a Coherent Ultra II Chameleon laser and a sensitive gallium arsenide phosphide (GaAsP) detector. Preparations were excited at $960 \mathrm{~nm}$, and emission was collected at 500-550 nm. Using a 20X water immersion objective, we acquired Z-stacks at $2 \mu \mathrm{m}$ intervals at a resolution of 1024 by 1024 pixels and up to $60-85 \mu \mathrm{m}$ of tissue depth.

Regions of interest corresponding to individual glomus cells were identified and analyzed in ImageJ. All regions of interest are included in the data. Fpre fluorescence was defined as the average fluorescence over the 4 frames immediately prior to the onset of the stimulus in the chamber. Mean and peak fluorescence was calculated over the duration when the stimulus was present in the imaging chamber. The ratio of Fstim/Fpre was calculated by dividing the mean and peak by Fpre just preceding the stimulus. Data acquisition and ROI analysis were carried out blinded to genotype.

\section{Metabolic imaging}

$H_{i g d 1 c^{+/+}}$and Higd1c $c^{-/}$animals were anesthetized with isoflurane and decapitated. Carotid bifurcations were dissected and cleaned in PBS to keep only the CB attached to the bifurcation. The preparation was then incubated in $50 \mu \mathrm{g} \mathrm{ml}^{-1}$ rhodamine 123 (ThermoFisher) in a physiological buffer (115 mM NaCl, $5 \mathrm{mM} \mathrm{KCl,} 24 \mathrm{mM} \mathrm{NaHCO}_{3}, 2 \mathrm{mM} \mathrm{CaCl}, 1 \mathrm{mM} \mathrm{MgCl}, 11$ $\mathrm{mM}$ glucose) at $26{ }^{\circ} \mathrm{C}$ in a tissue culture incubator with $5 \% \mathrm{CO}_{2}$ for 30 min before transfer to the recording chamber for imaging.

At baseline, the CB was superfused by gravity at $5 \mathrm{ml} \mathrm{min}{ }^{-1}$ with physiological buffer bubbling $95 \% \mathrm{O}_{2} / 5 \% \mathrm{CO}_{2}$ in the reservoir to maintain $\mathrm{PO}_{2} \sim 700 \mathrm{mmHg}$ and $\mathrm{pH} 7.4$ in the 
imaging chamber at $22^{\circ} \mathrm{C}$. Hypoxia down to $\mathrm{PO}_{2} \sim 10 \mathrm{mmHg}$ was generated by bubbling physiological buffer in the reservoir with $95 \% \mathrm{~N}_{2} / 5 \% \mathrm{CO}_{2}$ for $7.5 \mathrm{~min}$. $\mathrm{PO}_{2}$ was measured using a Clark style oxygen sensor (OX-50, Unisense). After 6 min of baseline recording, the preparation was stimulated with hypoxia for a period of $7.5 \mathrm{~min}$ followed by $7.5 \mathrm{~min}$ of recovery between stimuli. This was followed by $\mathrm{CN}(1 \mathrm{mM})$ and FCCP $(2 \mu \mathrm{M})$ for periods of $2.25 \mathrm{~min}$ each, with 7.5 min of recovery between stimuli.

Imaging was performed on a Zeiss LSM 7 MP two-photon microscope with a Coherent Ultra II Chameleon laser and a sensitive gallium arsenide phosphide (GaAsP) detector. Preparations were excited at $960 \mathrm{~nm}$, and emission was collected at 500-550 nm. Using a 20X water immersion objective, we acquired Z-stacks at $2 \mu \mathrm{m}$ intervals at a resolution of 1024 by 1024 pixels and up to $60-85 \mu \mathrm{m}$ of tissue depth.

Regions of interest (ROIs) corresponding to individual glomus cells were identified and analyzed in ImageJ. All regions of interest are included in the data except as indicated in specific analyses. Due to a linear decrease in baseline fluorescence over the time course of the experiment, baseline subtraction was performed. First, the fluorescence trace of each ROI was smoothed using a 3 point centered rolling average, and the baseline was calculated using linear interpolation between the inter-stimulus intervals. This baseline was then subtracted from the original traces. Fpre fluorescence was defined as the fluorescence immediately prior to the onset of the stimulus in the chamber. Mean and peak fluorescence were calculated over the duration when the stimulus was present in the imaging chamber. The ratio of Fstim/Fpre was calculated by dividing the mean and peak by Fpre just preceding the stimulus. Data acquisition and ROI analysis were carried out blinded to genotype.

\section{Mitochondrial biochemistry}

Mitochondrial fractions were obtained as previously described in $(24,32,33)$ from ten $80 \%$ confluent $15-\mathrm{cm}$ plates or from $1 \mathrm{~L}$ of liquid culture. Whole-cell extracts were obtained from 
pelleted cells solubilized in RIPA buffer (25 mM Tris- $\mathrm{HCl}(\mathrm{pH} 7.6), 150 \mathrm{mM} \mathrm{NaCl}, 1 \% \mathrm{NP}-40,1 \%$ sodium deoxycholate, and $0.1 \%$ SDS) with $1 \mathrm{mM}$ PMSF for $20 \mathrm{~min}$. Extracts were cleared after 5 min centrifugation at $15,000 \mathrm{rpm}$ at $4^{\circ} \mathrm{C}$.

Proteins from purified mitochondria were extracted in native conditions with either digitonin at a proportion of $1: 2$ of protein or with $n$-dodecyl- $\beta$-D-maltoside (DDM) at a concentration of $0.4 \%$. Samples were incubated on ice for $10 \mathrm{~min}$ and pelleted at $10,000 \times \mathrm{g}$ for 30 min at $4{ }^{\circ} \mathrm{C}$. Samples were prepared for Blue Native Electrophoresis and/or Complex I and Complex IV in-gel activity (IGA) assays as described (34). Immunoprecipitation of HIGD1CMyc-DDK-tagged proteins was performed using $1 \mathrm{mg}$ of mitochondria, extracted in $1.5 \mathrm{M}$ aminocaproic acid, $50 \mathrm{mM}$ Bis-Tris $\mathrm{pH} 7,1 \%$ digitonin, $1 \mathrm{mM} \mathrm{PMSF}$, and $8 \mu \mathrm{l}$ of protease inhibitor cocktail (Sigma, P8340) for $10 \mathrm{~min}$ on ice. Samples were pelleted at $10,000 \mathrm{x}$ g for 30 min at $4{ }^{\circ} \mathrm{C}$, and the extract (Ex) was incubated for $2-3 \mathrm{~h}$ at $4{ }^{\circ} \mathrm{C}$ with $30 \mu$ of FLAG-conjugated beads (anti-DYDDDDDK beads, Sigma) or empty beads (ThermoScientific), previously washed in PBS. Beads were washed 5 times in $1 \mathrm{~mL}$ of $1.5 \mathrm{M}$ aminocaproic acid, $50 \mathrm{mM}$ Bis-Tris $(\mathrm{pH}$ 7), $0.1 \%$ digitonin, and boiled for 5 min with $50 \mu$ of Laemmli buffer two times to release bound material. Representative amounts of all fractions were loaded on 14\% SDS-PAGE gels.

\section{Complex specific assay and oxygen consumption rate}

Mitochondrial respiratory chain Complex IV activity was performed according to established methods (35). Citrate synthase activity was used as a control. Enzymatic activities were expressed relative to the total amount of extracted protein.

Oxygen consumption rate (OCR) in normoxia was measured polarographically using a Clark-type electrode from Hansatech Instruments (Norfolk, United Kingdom) at $37^{\circ} \mathrm{C} . \sim 2 \times 10^{6}$ cells were trypsinized and washed with PBS, and then resuspended in $0.5 \mathrm{ml}$ of permeabilizedcell respiration buffer (PRB) containing $0.3 \mathrm{M}$ mannitol, $10 \mathrm{mM} \mathrm{KCl}, 5 \mathrm{mM} \mathrm{MgCl}, 0.5 \mathrm{mM}$ EDTA, $0.5 \mathrm{mM}$ EGTA, $1 \mathrm{mg} \mathrm{ml}^{-1} \mathrm{BSA}$, and $10 \mathrm{mM} \mathrm{KH}_{2} \mathrm{PO}_{4}(\mathrm{pH} 7.4)$ at $37^{\circ} \mathrm{C}$, supplemented 
with 10 units of hexokinase. The cell suspension was immediately placed into the polarographic chamber to measure endogenous respiration. Digitonin permeabilization $\left(0.02 \mathrm{mg} \mathrm{ml}^{-1}\right)$ was performed to assay substrate-driven respiration, using FADH-linked substrates (10 mM succinate plus $5 \mathrm{mM}$ glycerol-3-phosphate) in the presence of $2.5 \mathrm{mM}$ ADP (phosphorylation state). Oligomycin-driven ATP synthesis inhibition $\left(0.75 \mu \mathrm{g} \mathrm{m}^{-1}\right)$ was assayed to obtain the non-phosphorylating state. Maximal oxygen consumption was reached by successive addition of the uncoupler CCCP (up to $0.4 \mu \mathrm{M}$ ). $0.8 \mu \mathrm{M} \mathrm{KCN}$ was used to assess the mitochondrial specificity of the oxygen consumption measured, and values were normalized by total cell number.

High-resolution respirometry was used to determine mitochondrial oxygen consumption and ascorbate/TMPD-dependent respiration in normoxia and hypoxia. Measurements were performed in intact or digitonin-permeabilized cells, respectively, in an Oxygraph-2k (Oroboros Instruments). Assays were performed according to manufacturer's SUIT protocols, using 2$4 \times 10^{5}$ cells washed with PBS and resuspended in Mir05 medium, and results were normalized by cell number.

\section{Extraction of total mitochondrial cytochromes}

$8 \mathrm{mg}$ of mitochondria were extracted with $330 \mathrm{mM} \mathrm{KCl}, 50 \mathrm{mM}$ Tris- $\mathrm{HCl}(\mathrm{pH} 7.5)$, and $10 \%$ potassium deoxycholate. Samples were mixed by inversion three times and pelleted for 15 $\min$ at $40,000 \times g$ at $4^{\circ} \mathrm{C}$. The clear supernatant was transferred to a new tube, and a final concentration of $2 \%$ potassium cholate was added. The extract was divided into two equal aliquots in $1 \mathrm{ml}$ quartz cuvettes, and the baseline was established. Then, the reference aliquot was oxidized with potassium ferricyanide, and the other was reduced with a few grains of sodium dithionite. Differential reduced vs oxidized spectrum was recorded from 450 to $650 \mathrm{~nm}$. 


\section{Data analysis and statistics}

Data analysis and statistical tests were performed using Microsoft Excel, custom-written scripts in R, and GraphPad Prism software. All data are biological replicates. Group data were analyzed by the Shapiro-Wilk test to determine if data was normally distributed with the critical $W$ value set at a $5 \%$ significance level. Normally distributed data are presented as mean \pm standard error of the mean (SEM) and compared by two-way analysis of variance (ANOVA) followed by Tukey's test for all pairwise comparisons, Sidak correction for multiple pairwise comparisons, or Dunnett's test for multiple comparisons to a single group. For comparisons that included groups that did not fit the assumption of normal distribution, data are presented as box plots with median, $25^{\text {th }}$, and $75^{\text {th }}$ percentiles indicated and compared by Mann-Whitney $U$ tests followed by Holm-Sidak correction for multiple comparisons. The $Z$ test of proportions was used to compare the proportion of glomus cells with calcium responses at different thresholds. Chisquare test was performed to determine if the distributions of glomus cells responsive to different hypoxic stimuli were drawn from the same population. All tests were two-tailed. No statistical method was used to predetermine sample size.

\section{Acknowledgements}

We acknowledge Alex Diaz de Arce for assistance with RNAseq analysis, Kailyss Freeman and the UCSF VITAL Core for coordinating donor tissue, ACD Bio for BaseScope in situ hybridization, Blair Gainous, Pauline Colombier, Brian Black, and the CVRI Transgenic Mouse Core for guidance and technical support in generating Higd1c mutant mice, Chris Allen for use of his two-photon microscope and cryostat, and the UCSF Nikon Imaging Center for use their widefield microscope. We sincerely thank Donor Network West, and most importantly the organ donors and their families, who give this precious gift to further scientific research.

The work was supported by a Canadian Institute of Health Research (201603PJT/366421 to R.J.A.W), a NIGMS-R35 grant (GM118141 to A.B.), and a Sandler 
Program for Breakthrough Biomedical Research New Frontier Award and UCSF CVRI (A.C.).

A.T. was supported by a Muscular Dystrophy Association (MDA) Development Grant (MDA 862896), A.G. by an UCSF Transplant T32 FAVOR grant (P0548805), and J.G. by an UCSF Physician-Scientist Scholars Program (PSSP) grant. RJAW is an AlHS Senior Scholar. 
Figure 1. Higd1c expression in carotid body glomus cells is reduced in Higd1c CRISPR mutants.

a, Expression of genes encoding four atypical mitochondrial electron transport chain (ETC) subunits in the carotid body (CB) versus adrenal medulla (AM) (8). RPKM, reads per kilobase per million reads mapped. $\mathrm{n}=3$ cohorts of 10 animals each. Data as mean \pm SEM. ${ }^{* *} \mathrm{p}<0.01$, ${ }^{* * * *} \mathrm{p}<0.0001$ by two-way ANOVA with Sidak correction. b, Expression of atypical ETC proteins in human $C B$ and adrengal gland (AG). AG, one RNA sample of adrenal glands pooled from 62 males and females, 15-61 years old. CB, two RNA samples of CBs from one male and one female adult. Dotted line, $100 \%$ of GAPDH expression. Data as mean. c, FLAG-tagged mouse and human HIGD1C (green) overexpressed in HEK293T cells co-localizes with the mitochondrial marker HSP60 (red) by immunostaining. DAPI, nuclear marker. Scale bar, 10 $\mu \mathrm{m}$. d, e, BaseScope in situ hybridization of a wild-type C57BL/6J carotid bifurcation. e, Boxed region from d. CB, carotid body. SCG, superior cervical ganglion. CA, internal and external carotid arteries. Arrowheads, glomus cells. Arrows, SCG neurons. Scale bar, $100 \mu \mathrm{m}$ (d), 10 $\mu \mathrm{m}(\mathrm{e})$. f, Expression of Higd1c mRNA is reduced in CBs from Higd1c mutants measured by RT-qPCR. $n=3(3-1,5-3)$ and 6 (1-1) samples. Each sample was prepared from 4 CBs from 2 animals. Data as mean \pm SEM. ${ }^{* *} \mathrm{p}<0.01$ by two-way ANOVA with Sidak correction. $\mathrm{g}, \mathrm{h}$, Immunostaining of CB glomus cells. TH, tyrosine hydroxylase. DAPI, nuclear marker. Scale bar, $50 \mu \mathrm{m}$. i, Quantitation of TH+ cells found no significant differences between CBs from $\mathrm{Higd}_{1} \mathrm{C}^{+/+}$and $\mathrm{Higd} 1 \mathrm{c}^{-/-}$animals of each allele or between alleles by two-way ANOVA with Sidak correction. $\mathrm{n}=5-7$ CBs from 3-7 animals. Data as mean \pm SEM.

\section{Figure 2. Ventilatory responses of Higd1c mutants to hypoxia and hypercapnia.}

a-h, Respiratory rate $(\mathrm{RR})$, tidal volume $(\mathrm{TV})$, and minute ventilation $(\mathrm{MV})$ (minute ventilation = respiratory rate $\times$ tidal volume) by whole body plethysmography of unrestrained, unanesthetized Higd1c $1-1^{+/+}$and Higd1c $1-1^{-/}$animals exposed to hypoxia (a-d) or hypercapnia (e-h). d, 
Hypoxic response as percentage change in hypoxia $\left(10 \% \mathrm{O}_{2}\right)$ versus control $\left(21 \% \mathrm{O}_{2}\right)$. $\mathrm{h}$, Hypercapnic response as percentage change in hypercapnia $\left(5 \% \mathrm{CO}_{2}\right)$ versus control $(0 \%$ $\left.\mathrm{CO}_{2}\right)$. Ventilatory parameters of $\mathrm{Higd}_{1} \mathrm{c}^{+/}$and $\mathrm{Higd}_{1} \mathrm{c}^{-/}$animals in normal air conditions $(21 \%$ $\mathrm{O}_{2}$ or $\left.0 \% \mathrm{CO}_{2}\right)$ are not significantly different $(\mathrm{p}>0.05) . \mathrm{n}=11(+/+), 11(-/-)$ animals. Data as mean \pm SEM. ${ }^{*} p<0.05,{ }^{* *} p<0.01,{ }^{* * *} p<0.001,{ }^{* * *} p<0.0001$ by two-way ANOVA with Tukey's test (a-c, e-g) or with Sidak correction $(d, h)$.

Figure 3. Higd1c mutants have defects in carotid body sensory responses to hypoxia a, b, Quantification of carotid sinus nerve activity in Higd1c $1-1^{+/+}$and Higd1c $1-1^{-/-}$tissue preparations at baseline (a) and in hypoxia $\left(\mathrm{PO}_{2}=80,60\right.$, and $\left.40 \mathrm{mmHg}\right)$ or hypercapnia $\left(\mathrm{PCO}_{2}=60 \mathrm{mmHg}\right)(\mathrm{b}) . \mathrm{n}=7(+/+), 10(-/-)$ preparations from 5 and 6 animals, respectively. Data as box plots showing median and interquartile interval. ${ }^{* *} p<0.01,{ }^{* *} p<0.001,{ }^{* * *} p<0.0001$ by Mann-Whitney U test with Holm-Sidak correction. d, e, Peak (d) and mean (e) GCaMP calcium responses (F/F0) of glomus cells from Higd1c $1-1^{+/+}$and Higd1c $1-1^{-/-}$animals to low $\mathrm{pH}(6.8)$, hypoxia $\left(\mathrm{PO}_{2}=50\right.$ and $\left.25 \mathrm{mmHg}\right)$, high $\mathrm{KCl}(40 \mathrm{mM})$, and cyanide $(\mathrm{CN}, 1 \mathrm{mM})$. Data as box plots showing median, interquartile interval, and max/min. $n=296 / 4 / 3(+/+), 201 / 4 / 3$ (-/-) for pH 6.8, 312/5/4 (+/+), 214/5/4 (-/-) for all other stimuli. $n$ as cells/CBs/animals. ${ }^{*} p<0.05$, ${ }^{* * * *} p<0.0001$ by Mann-Whitney U test with Holm-Sidak correction.

Figure 4. HIGD1C regulates the hypoxic response of the electron transport chain in carotid body glomus cells.

a-e, Change in fluorescence of glomus cells in Higd1c $1-1^{+/+}$and Higd1c 1-1 $1^{--}$CBs loaded with rhodamine 123, a dye sensitive to mitochondrial inner membrane potential, in response to hypoxia $\left(\mathrm{PO}_{2}<80 \mathrm{mmHg}\right)$, cyanide $(1 \mathrm{mM})$, and FCCP $(8 \mu \mathrm{M})$. Data from all glomus cells $(\mathrm{a}, \mathrm{b})$ or only glomus cells with responses to FFCP at $\Delta F / F>0.2$ (c-e). a, c, d, Dashed line, 
fluorescence at the start of stimulus. a, b, $n=291 / 3 / 3(+/+), 312 / 3 / 3(-/-)$ cells/CBs/animals. c-e, n=98/3/3 (+/+), 102/3/3 (-/-) cells/CBs/animals. a, c, d, Data as median and interquartile interval. e, Data as box plots showing median and interquartile interval. a, c-e, ${ }^{* *} \mathrm{p}<0.01$, ${ }^{* * *} p<0.001,{ }^{* * *} p<0.0001$ by Mann-Whitney $U$ test with Holm-Sidak correction. b, Fraction of glomus cells that responded to FCCP at different $\Delta \mathrm{F} / \mathrm{F} .{ }^{*} \mathrm{p}<0.01,{ }^{* * *} \mathrm{p}<0.001,{ }^{* * * *} \mathrm{p}<0.0001$ by $\mathrm{Z}$ test of proportions.

Figure 5. HIGD1C is a mitochondrial protein that associates with the electron transport chain Complex IV and regulates cellular respiration.

a-g, HIGD1A-KO HEK293T cells overexpressing FLAG-tagged human or mouse HIGD1C and/or COX4 isoforms. EV, empty vector. HIGD1C, human HIGD1C. Higd1c, mouse HIGD1C. a, BN-PAGE and immunoblots using antibodies for FLAG and the Complex IV subunit COX5B. SDHA is used as a loading control. b, Co-immunoprecipitation using a FLAG antibody followed by SDS-PAGE and immunoblot using antibodies for FLAG and subunits of Complex I (NDUFA9), Complex II (SDHA), Complex III (CORE2, UQCRB), Complex IV (COX1, COX4I1, COX5B), and cytochrome c. c, ETC complexes and supercomplexes extracted with DDM and digitonin, respectively, detected by BN-PAGE and immunoblotting. $d$, Complex IV enzymatic activity assay. $n=3$. Data as mean \pm SEM. ${ }^{*} p<0.05,{ }^{* *} p<0.01,{ }^{* * *} p<0.001,{ }^{* * * *} p<0.0001$ by one-way ANOVA with Dunnett test. " $\mathrm{p}$-value versus WT, +p-value versus HIGD1A-KO+EV. Grey color indicates $p=0.06$. e, Relative peak height of heme $a+a 3$ normalized by cytochrome $b$ peak. $n=3$. Data as mean \pm SEM. ${ }^{* *} p<0.01$ by one-way ANOVA with Dunnett test. $f$, Ascorbate/TMPD-dependent oxygen consumption in normoxia (Nox, $\mathrm{PO}_{2}=150 \mathrm{mmHg}$ ) and hypoxia ( $\mathrm{Hox}, \mathrm{PO}_{2}=25 \mathrm{mmHg}$ ) by high-resolution respirometry. Values normalized by cell number. $n=6$. $g$, Ratio of hypoxic/normoxic oxygen consumption calculated in $f$. $f-g$, Data as mean \pm SEM. ${ }^{* *} p<0.01,{ }^{* *} p<0.001,{ }^{* * *} p<0.0001$ by two-way ANOVA with Sidak correction. 


\section{Figure S1. Generation and mapping of Higd1c CRISPR mutants}

a, Schematic representation of mRNA transcripts of Higd1c and Mettl7a2 and a fusion transcript spanning both genes named Methig1. Boxes denote exons. Arrow, Higd1c translational start site. Two sgRNAs targeting sequences upstream of exon 1 and within exon 3 (first coding exon) of Higd1c were injected together with Cas9 mRNA into C57BL/6J embryos. Six founders were generated, from which 8 alleles were identified by sequencing around the sgRNA target sites. Mutant alleles isolated included short indels around the sgRNA target sequence in exon 3 and deletions that spanned the regions between the two guides. Arrow denotes the start codon of Higd1c in exon 3. FS, frameshift mutation. $\varnothing$, no transcript or truncated transcript starting in exon 4. b, Genotyping primers for large deletion and small indel Higd1c alleles. All mapped mutations abolish a restriction site for Kpn2I in exon 3. c, PCR with P11/P8 primer pair used to genotype the large deletion 3-1 allele. PCR with P9/P8 primer pair followed by restriction digest with Kpnl used to genotype small indels in exon 3. d, Expected changes to the amino acid sequence of HIGD1C in mutant alleles.

\section{Figure S2. Higd1c is highly expressed in the CB compared to other tissues}

a-d, qRT-PCR targeting Higd1c mRNA transcripts containing 5 exons (a, c) or 4 exons (b, d) in

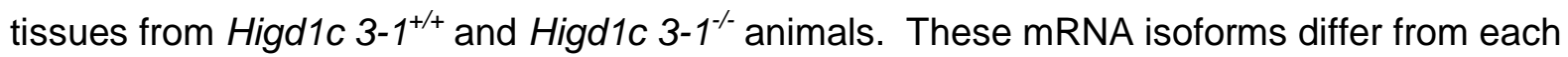
other only in the first two exons that encode 5' UTR; the 4 exon isoform does not contain Exon 2 (Fig. S1a). Higd1c expression normalized to Actb encoding $\beta$-actin by template and day of the experiment. Dotted line, $1 \%$ of the CB expression level. AM, adrenal medulla. CB, carotid body. PG/NG/JG, petrosal ganglion/nodose ganglion/jugular ganglion. $\mathrm{MO}$, medulla oblongata. Ctx, cerebral cortex. OB, olfactory bulb. SCG, superior cervical ganglion. For CB, $n=3 / 6$ (a) and 4/8 (b) samples/animals with 4 CBs from 2 animals pooled per sample. For kidney AM, $n=8 / 8$ samples/animals $(c, d)$. For all others, $n=3 / 3$ or $4 / 4$ samples/animals $(a-d)$. Data as mean and SEM. ${ }^{* \star * *} \mathrm{p}<0.0001$ by two-way ANOVA with Sidak correction. Because Actb 
expression can vary between tissues, we used Higd1c 3-1/- tissues carrying a deletion that abolishes one primer target site as a negative control for Higd1c expression. e, Expression of select mitochondrial ETC subunits by single-cell RNAseq of 7 mouse glomus cells from a previously published dataset (15). One cell from this study was excluded from analysis because it had little to no expression of genes known to be expressed at high levels in mouse glomus cells, such as Olfr78, Epas1, Cox4i2, and Ndufa4l2 $(4,8)$. RPKM, reads per kilobase per million reads mapped. Data presented as the median and interquartile interval. Dotted line, RPKM level corresponding to no reads. f, Expression in total RNA from human tissues of select mitochondrial ETC subunits and other genes known to be expressed in the CB. Unlike its expression in mice, the tyrosine hydroxylase gene $\mathrm{TH}$ is expressed in only a subset of glomus cells in the adult human $\mathrm{CB}(36,37)$. The olfactory receptor gene OR51E2 is the ortholog of mouse Olfr78, one of the most highly upregulated genes in the CB versus adrenal medulla in mice (8). AG, one RNA sample of adrenal glands pooled from 62 males and females, 15-61 years old. CB, two RNA samples of carotid bodies from two transplant donors, a 55 year-old male and a 35 year-old female. Dotted line, $100 \%$ of GAPDH expression. Data presented as the mean.

\section{Figure S3. Higd1c is expressed in glomus cells of the carotid body.}

a-o, BaseScope in situ hybridization to detect mRNA transcripts in adjacent sections of the

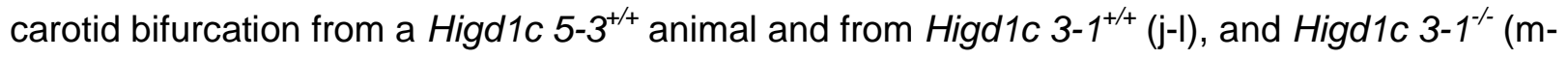
o) animals. c, f, i, l, and o, Boxed regions from b, e, h, k, and n, respectively. a-c, dapB probes are negative controls that target bacterial genes. $d-f, P p i b$ and Polr2a are positive control probes for mouse transcripts expressed ubiquitously. g-o, Probes that target transcripts for Higd1c and tyrosine hydroxylase (Th), a marker of glomus cells. The large deletion in the Higd1c 3-1 allele removes the target sequence of BaseScope probes for Higd1c. Scale bars, $200 \mu \mathrm{m}(\mathrm{a}, \mathrm{d}, \mathrm{g}, \mathrm{j}$, and m), $50 \mu \mathrm{m}$ (b, e, h, k, and n), and $10 \mu \mathrm{m}$ (c, f, I, I, and o). 
Figure S4. Higd1c expression in kidney proximal tubules is attenuated in Higd1c mutants.

a-d, Staining of the kidney from a wild-type C57BL/6J (B6) animal with fluorescein-conjugated Lotus tetragonolobus lectin (LTL) that binds to the apical surface of proximal tubules and an antibody for CD31, a marker of endothelial cells. DAPI, nuclear marker. Scale bar, $50 \mu \mathrm{m}$. e-p, BaseScope in situ hybridization to detect mRNA transcripts in sections of the kidney from a wildtype C57BL/6J (B6) animal (e-m) and from a Higd1c 3-1/- mutant (n-p). g, j, m, and p, Boxed regions from $\mathrm{f}, \mathrm{i}, \mathrm{I}$, and $\mathrm{o}$, respectively. e-g, dapB probes are negative controls that target bacterial genes. h-j, Ppib and Polr2a are positive control probes for mouse transcripts expressed ubiquitously. k-p, Probes that target transcripts for Higd1c and tyrosine hydroxylase (Th), a marker of glomus cells. The large deletion in the Higd1c 3-1 allele removes the target sequence of BaseScope probes for Higd1c. Scale bars, $200 \mu \mathrm{m}(\mathrm{e}, \mathrm{h}, \mathrm{k}$, and n), $50 \mu \mathrm{m}$ (f, i, I, and o), and $10 \mu \mathrm{m}(\mathrm{g}, \mathrm{j}, \mathrm{m}$, and p). q, Expression of Higd1c mRNA is reduced in kidneys from Higd1c mutants as measured by qRT-PCR. The target region of one primer of the primer pair is deleted in the Higd1c 3-1 allele. $\mathrm{n}=6$ (3-1, 5-3), 12 (1-1) kidneys from 6 and 12 animals, respectively. Data as mean \pm SEM. ${ }^{* * * *} \mathrm{p}<0.0001$ by two-way ANOVA with Sidak correction.

\section{Figure S5. Ventilatory responses of Higd1c 3-1 and 5-3 animals to hypoxia and}

\section{hypercapnia.}

a-s, Respiratory rate $(\mathrm{RR})$, tidal volume $(\mathrm{TV})$, and minute ventilation $(\mathrm{MV})$ (minute ventilation = respiratory rate $\times$ tidal volume) by whole-body plethysmography of unrestrained, unanesthetized $H_{i g d 1} c^{+/}$and Higd1 $c^{-/}$animals. a-c, Time course of experiments on Higd1c 1-1 allele showing periods of normoxia (Nox), hypoxia (Hox), and hypercapnia (Hc). d-k, Ventilation of Higd1c ${ }^{+/+}$ and Higd $1 \mathrm{c}^{-/}$animals of 3-1 (d-g) and 5-3 alleles (h-k) exposed to hypercapnia. g, k, Hypoxic response as percentage change in hypoxia $\left(10 \% \mathrm{O}_{2}\right)$ versus control $\left(21 \% \mathrm{O}_{2}\right)$. I-s, Ventilation of

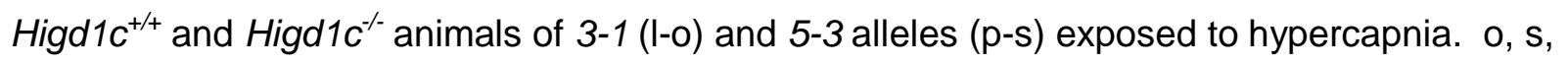


Hypercapnic response as percentage change in hypercapnia $\left(5 \% \mathrm{CO}_{2}\right)$ versus control $(0 \%$ $\left.\mathrm{CO}_{2}\right)$. Ventilatory parameters of $\mathrm{Higd}_{1} \mathrm{c}^{+/+}$and $\mathrm{Higd}_{1} \mathrm{c}^{-/}$animals in normal air conditions $(21 \%$ $\mathrm{O}_{2}$ or $\left.0 \% \mathrm{CO}_{2}\right)$ are not significantly different $(\mathrm{p}>0.05) . \mathrm{n}=11\left(1-1^{+/+}\right), 11\left(1-1^{-/}\right), 9\left(3-1^{+/+}\right), 12(3-$ $\left.1^{-/}\right), 11\left(5-3^{+/+}\right), 9\left(5-3^{-/}\right)$animals. Data as mean \pm SEM. ${ }^{*} p<0.05,{ }^{* *} p<0.01,{ }^{* * *} p<0.001$, ${ }^{* * * *} p<0.0001$ by two-way ANOVA with Tukey's test (d-f, h-j, I-n, p-r) or with Sidak correction (g, $k, 0, s)$.

Figure S6. Calcium responses of Higd1c 1-1 glomus cells to sensory stimuli

a, b, Representative traces of carotid sinus nerve (CSN) activity from Higd1c $1-1^{+/+}$and Higd1c $1-1^{-/}$tissue preparations exposed to hypoxia $\left(\mathrm{PO}_{2}=80,60\right.$, and $\left.40 \mathrm{mmHg}\right)$ or hypercapnia $\left(\mathrm{PCO}_{2}=60 \mathrm{mmHg}\right)$ normalized to activity in impulses $/ \mathrm{s}$ at $\mathrm{t}=0 . \mathrm{c}, \mathrm{d}$, Individual traces of GCaMP fluorescence of glomus cells from Higd1 $\mathrm{c}^{+/+}$and $\mathrm{Higd1} \mathrm{c}^{-/-}$animals, normalized to fluorescence at $\mathrm{t}=0 \mathrm{~s}$. Z stacks collected every $45 \mathrm{~s}$. e, f, Scatter plot of peak responses individual glomus cells to two levels of hypoxia $\left(\mathrm{PO}_{2}=50\right.$ and $\left.25 \mathrm{mmHg}\right)$ in CBs from Higd1c $\mathrm{c}^{+/+}(\mathrm{e})$ and Higd1c $\mathrm{c}^{-/}(\mathrm{f})$ animals. Strong responders have F/F0>1.5 as delineated by dashed lines. g, Fraction of cells responding to mild hypoxia $\left(\mathrm{PO}_{2}=50 \mathrm{mmHg}\right)$ with peak $\mathrm{F} / \mathrm{FO}$ above the threshold on the $\mathrm{x}$-axis. ${ }^{* * *} p<0.001$ by $Z$ test of proportions. $h$, Fraction of cells that respond to hypoxia $\left(\mathrm{PO}_{2}=50\right.$ and/or $25 \mathrm{mmHg}$ ) as subdivided in e and $\mathrm{f} .{ }^{* * *} \mathrm{p}<0.0001$ by Chi-square test. $n=296 / 4 / 3(+/+), 201 / 4 / 3$ $(-/-) . \mathrm{n}$ as cells/CBs/animals.

Figure S7. HIGD1C regulates the hypoxic response of the electron transport chain in carotid body glomus cells.

a, Fluorescence of a whole-mount carotid body loaded with rhodamine 123 (Rh123), a dye sensitive to changes in mitochondrial inner membrane potential, under quenching conditions. Arrowheads, glomus cell clusters. Asterisk, vasculature. Scale bar, $50 \mu \mathrm{m}$. b-f, Change in Rh123 fluorescence of cells in Higd1c $1-1^{+/+}$and Higd1c $1-1^{-}$CBs in response to hypoxia 
$\left(\mathrm{PO}_{2}<80 \mathrm{mmHg}\right)$, cyanide $(1 \mathrm{mM})$, and FCCP $(8 \mu \mathrm{M})$. b, c, Time course of fluorescence relative to start of hypoxia stimulus. Data from all glomus cells (b) or only glomus cells with responses to FFCP at $\Delta F / F>0.2(c-f)$. All vascular cells analyzed responded to $F C C P$ with $\Delta F / F>0.2$. b-C, Dashed blue line, normoxic $\mathrm{PO}_{2}=100 \mathrm{mmHg}$ comparable to well-oxygenated arterial blood. b-d, Dashed black line, fluorescence at the start of the stimulus. e, Dashed black line, $\Delta F / F$ at normoxia. b, $n=291 / 3 / 3(+/+), 312 / 3 / 3(-/-)$ glomus cells/CBs/animals. c-f, $n=98 / 3 / 3(+/+)$, 102/3/3 (-/-) glomus cells/CBs/animals. d-f, 49/3/3 (+/+) vascular cells/CBs/animals. b-e, Data as median and interquartile interval. f, Data as box plots showing median, interquartile interval, and max/min. b-f, ${ }^{* *} p<0.01,{ }^{* * *} p<0.001,{ }^{* * *} p<0.0001$ by Mann-Whitney U test with Holm-Sidak correction.

\section{Figure S8. HIGD1C overexpression in wild-type HEK293T cells inhibits CIV activity} a-f, HEK293T cells overexpressing FLAG-tagged human or mouse HIGD1C or/and COX4I1/I2 isoforms. EV, empty vector. HIGD1C, human HIGD1C. Higd1c, mouse HIGD1C. a, SDS-PAGE and immunoblot using FLAG antibody to detect overexpression of different proteins. b, SDSPAGE and immunoblots using antibodies for FLAG and ETC subunits. c, Coimmunoprecipitation using a FLAG antibody followed by SDS-PAGE and immunoblotting. d, BNPAGE and immunoblotting from purified mitochondria extracted with DDM to analyze ETC complexes. e, Mitochondrial extracts solubilized with digitonin and analyzed by immunoblotting against antibodies for ETC complexes I, II, III and IV or by in-gel activity assays. f-g, Spectrophotometric measurement of CIV (f) or citrate synthase (g) activities in whole-cell extracts. Enzyme activities are expressed as a fraction of WT values. $n=3$. Data as mean \pm SEM. ${ }^{*} p<0.05,{ }^{* * *} p<0.001$ by one-way ANOVA with Dunnett test. ${ }^{*} p$-value versus WT, $+p-$ value versus WT+HIGD1C, \#p-value versus WT+Higd1c. $h$, Polarographic assessment in digitonin-permeabilized cells of $\mathrm{KCN}$-sensitive oxygen consumption driven by succinate and 
glycerol-3-phosphate, in the presence or absence of ADP, oligomycin, and the uncoupler CCCP. $n=3$. i, Respiratory control ratio of the measurements performed in $h$. Data as mean \pm SEM. ${ }^{*} \mathrm{p}<0.05,{ }^{* *} \mathrm{p}<0.01,{ }^{* * *} \mathrm{p}<0.0001$ by one-way ANOVA with Dunnett test compared to WT.

Figure S9. HIGD1C overexpression in HIGD2A-KO HEK293T cells does not rescue ETC defects

a-f, HIGD2A-KO cells overexpressing FLAG-tagged human or mouse HIGD1C. EV, empty vector. HIGD1C, human HIGD1C. Higd1c, mouse HIGD1C. a, SDS-PAGE and immunoblots using FLAG and ETC subunits. b, BN-PAGE of digitonin-permeabilized purified mitochondria and immunoblot using FLAG and COX5B antibodies, and SDHA as a loading control. c, Coimmunoprecipitation using a FLAG antibody followed by SDS-PAGE and immunoblotting. d, BNPAGE and immunoblotting using purified mitochondria solubilized with DDM or digitonin, to analyze ETC complexes and supercomplexes, respectively. e-f, CIV and citrate synthase activities analyzed by polarography in whole-cell extracts. Enzyme activities are expressed as a fraction of WT values. $n=3$. Data as mean \pm SEM. ${ }^{* * * *} p<0.0001$ by one-way ANOVA with Dunnett test. ${ }^{* * *} \mathrm{p}<0.0001$ versus $\mathrm{WT},++++\mathrm{p}<0.0001$ versus $H I G D 2 A-K O+E V$.

Figure S10. HIGD1C associates with CIV in HIGD1A-KO HEK293T cells and restores some ETC functions mediated by HIGD1A

a-f, HIGD1A-KO cells overexpressing FLAG-tagged human or mouse HIGD1C or/and COX4I1/I2 isoforms. EV, empty vector. HIGD1C, human HIGD1C. Higd1c, mouse HIGD1C. a, SDS-PAGE and immunoblots detecting FLAG and ETC subunits. b, SDS-PAGE and immunoblot using FLAG antibody to detect overexpression of the different proteins. c, SDSPAGE and immunoblot using COX4I1 and COX4I2 antibodies to detect gene knockdown and overexpression, respectively. d, Co-immunoprecipitation using a FLAG antibody followed by SDS-PAGE and immunoblotting. e, BN-PAGE and immunoblotting using purified mitochondria 
solubilized with DDM or digitonin, to analyze ETC complexes and supercomplexes, respectively.

** indicates the accumulation of cytochrome $c$ in an unidentified subcomplex. $f$, Citrate synthase activity measured by polarography in whole-cell extracts and expressed as a fraction of WT values. $n=3$. g, Polarographic assessment in digitonin-permeabilized cells of KCN-sensitive oxygen consumption driven by succinate and glycerol-3-phosphate, in the presence or absence of ADP (basal respiration and phosphorylating), oligomycin (resting), and the uncoupler CCCP (uncoupled). $\mathrm{n}=3$. Data as mean \pm SEM. ${ }^{*} \mathrm{p}<0.05,{ }^{* *} \mathrm{p}<0.01,{ }^{* * *} \mathrm{p}<0.001$ vs. HIGD $1 A-\mathrm{KO}+\mathrm{EV}$ by two-way ANOVA with Dunnett test. h, Respiratory control ratio of the measurements performed in f. i, BN-PAGE and immunoblotting using digitonin-solubilized whole cells treated with DDM to analyze the levels of CIV. SDHA is used as a loading control.

\section{Figure S11. HIGD1C overexpression alters the oxygen binding domain of Complex IV in HIGD1A-KO HEK293T cells.}

a, Differential spectra (reduced minus oxidized) of total mitochondrial cytochromes measured by spectrophotometry. Absorbance of cytochromes extracted from purified mitochondria was measured from $450-650 \mathrm{~nm}$. The panel on the left is a $2.5 \mathrm{X}$ magnification on the $\mathrm{x}$-axis of the indicated portion of the graph. The grey vertical line indicates the wild-type heme $a+a_{3}$ peak at $603 \mathrm{~nm}$. The green vertical line marks the $599 \mathrm{~nm}$ wavelength, towards which some of the heme $a+a_{3}$ peaks are shifted. b-c, Relative peak height of $a+a 3$ (b) or cytochrome b (c) shown as ratio of WT. d, Relative peak area a+a3 measured as ratio of WT. e, Relative peak base width of $a+a 3$ represented as ratio of WT. b-e, $n=3$. Data as mean \pm SEM. ${ }^{*} p<0.05$, ${ }^{* *} p<0.01$ by oneway ANOVA with Dunnett test. 
Table S1. Genotype distribution of progeny from Higd1c ${ }^{+/-} \times \mathrm{Higd1c}^{+/-} \mathrm{crosses}^{-}$

\begin{tabular}{|c|c|c|c|c|c|}
\hline Higd1c Allele & $\mathrm{N}$ & \multicolumn{3}{|c|}{ Frequency of Genotype } & Chi-square $\mathrm{p}$ value \\
\hline & & $+/+$ & $+/-$ & $-/-$ & \\
\hline $3-1$ & 125 & 0.22 & 0.48 & 0.30 & 0.344 \\
\hline $1-1$ & 233 & 0.32 & 0.43 & 0.25 & 0.028 \\
\hline $5-3$ & 78 & 0.24 & 0.53 & 0.23 & 0.891 \\
\hline
\end{tabular}

Table S2. Reagents and resources

\begin{tabular}{|c|c|c|}
\hline Reagent or resource & Source & Identifier \\
\hline \multicolumn{3}{|l|}{ Mouse strains } \\
\hline C57BL/6J (wild-type) & JAX & 000664 \\
\hline B6.FVB(Cg)-Tg(Th-cre) ${ }^{\text {Flit2Gsat } / M m u c d ~}$ & MMRRC & 031029-UCD \\
\hline B6;129S-Gt(ROSA)26Sor ${ }^{\text {tm38(CAG-GCaMP3)Hze }} / \mathrm{J}$ & JAX & 014538 \\
\hline B6. Higd1c 3-1 & This paper & \\
\hline B6. Higd1c 1-1 & This paper & \\
\hline B6.Higd1c 5-3 & This paper & \\
\hline \multicolumn{3}{|l|}{ sgRNA primers (target sequence in bold) } \\
\hline $\begin{array}{l}\text { sgRNA-1 (forward): } \\
\text { TAATACGACTCACTATAGGGAGTCTCTCGATTTCCGG } \\
\text { GTTTTAGAGCTAGAA }\end{array}$ & This paper & \\
\hline $\begin{array}{l}\text { sgRNA-2 (forward): } \\
\text { TAATACGACTCACTATAGGCTGATTTAAGGAGTGAG } \\
\text { TGCGTTTTAGAGCTAGAA }\end{array}$ & This paper & \\
\hline $\begin{array}{l}\text { sgRNA (reverse, common): } \\
\text { AAAAAAAGCACCGACTCGGTGCCACTTTTTCAAGTTG } \\
\text { ATAACGGACTAGCCTTATTTTAACTTGCTATTTCTAGC } \\
\text { TCTAAAAC }\end{array}$ & This paper & \\
\hline \multicolumn{3}{|l|}{ Genotyping primers } \\
\hline Higd1c-P8: GTCAGGTGGCCCCTGATGAAA & This paper & \\
\hline Higd1c-P9: GTGCACGAGCAGACTGGTTCT & This paper & \\
\hline Higd1c-P11: GGATATCACAGCCACAGAGGACG & This paper & \\
\hline \multicolumn{3}{|l|}{ qPCR primers } \\
\hline Actb-F: AGCCATGTACGTAGCCATCC & This paper & \\
\hline Actb-R: GCCATCTCTTGCTCGAAGTC & This paper & \\
\hline Higd1c (5 exon)-F: CACGTACAAGGGCTGCATGG & This paper & \\
\hline Higd1c (5 exon)-R: ACCTAGAGTCACGGCTCCC & This paper & \\
\hline Higd1c (4 exon)-F: CCAGCACGTACAAGAGAGAAA & This paper & \\
\hline Higd1c (4 exon)-R: ACGTGGATGAGATGAAGGGAC & This paper & \\
\hline GADPH-F: ACCACAGTCCATGCCATCAC & $(38)$ & \\
\hline GADPH-R: TCCCACCACCCTGTTGCTGTA & $(38)$ & \\
\hline
\end{tabular}




\begin{tabular}{|c|c|c|}
\hline HIGD1A-F1: CAACAGACACAGGTGTTTCC & This paper & \\
\hline HIGD1A-R1: CAATTGCTGCAAAACCCGCT & This paper & \\
\hline HIGD2A-F: GCCCCACTGTTTACAGGAAT & This paper & \\
\hline HIGD2A-R: GCGCATCATGAGCTGAGAG & This paper & \\
\hline HIGD1C-F: GAAGGCCAATTATCCCGACT & This paper & \\
\hline HIGD1C-R: GCTTGTAAAGACCACAGGAC & This paper & \\
\hline COX4I1-F: CAAGCGAGCAATTTCCACCT & This paper & \\
\hline COX4I1-R: CCTTCTCCTTCAATGCCTTC & This paper & \\
\hline COX4I2-F: GAGGGATGCACAGCTCAGAA & This paper & \\
\hline COX4I2-R: CTTCTCCTTCTCCTTCAGGG & This paper & \\
\hline NDUFA4L2-F: GATGATCGGCTTAATCTGCC & This paper & \\
\hline NDUFA4L2-R: GTATTGGTCATTGGGGCTCA & This paper & \\
\hline TH-F: GCTGGACAAGTGTCATCACCTG & OriGene & HP234519 \\
\hline TH-R: CCTGTACTGGAAGGCGATCTCA & OriGene & HP234519 \\
\hline OR51E2-F2: TCATCCCATTGTGCGTGTTG & This paper & \\
\hline OR51E2-R2: CACCCGTGTTCTGATCTGTTTG & This paper & \\
\hline \multicolumn{3}{|l|}{ BaseScope in situ hybridization probes } \\
\hline BA-Mm-Higd1c-2zz-st & ACD & 862241 \\
\hline BA-Mm-Th-3EJ-C2 & ACD & $854771-C 2$ \\
\hline dapB-1ZZ-C1/dapB-1ZZ-C2 & ACD & 700141 \\
\hline Mm-Ppib-1ZZ & $A C D$ & 701081 \\
\hline Mm-Polr2a-1ZZ-C2 & ACD & $701101-\mathrm{C} 2$ \\
\hline \multicolumn{3}{|l|}{ Plasmids } \\
\hline HIGD1C-Myc-FLAG in pCMV6-Entry (human) & OriGene & RC225015 \\
\hline Higd1c-Myc-FLAG in pCMV6-Entry (mouse) & OriGene & MR220387 \\
\hline COX4I1-Myc-FLAG in pCMV6-Entry & OriGene & RC209374 \\
\hline COX4I2-Myc-FLAG in pCMV6-Entry & OriGene & RC209204 \\
\hline pCMV6-A-Entry-Hygro & OriGene & PS100024 \\
\hline pCMV6-A-Entry-BSD & OriGene & PS100022 \\
\hline HIGD1A-Myc-FLAG in pCMV6-A-Entry-Hygro & $(24)$ & \\
\hline HIGD2A-Myc-FLAG in pCMV6-A-Entry-Hygro & $(24)$ & \\
\hline HIGD1C-Myc-FLAG in pCMV6-A-Entry-Hygro (human) & This paper & \\
\hline Higd1c-Myc-FLAG in pCMV6-A-Entry-Hygro (mouse) & This paper & \\
\hline COX4I1-Myc-FLAG in pCMV6-A-Entry-BSD & This paper & \\
\hline COX4I2-Myc-FLAG in pCMV6-A-Entry-BSD & This paper & \\
\hline \multicolumn{3}{|l|}{ Primary Antibodies/Stains } \\
\hline mouse anti-DDK/FLAG & OriGene & TA50011 \\
\hline mouse anti-HSP60 & ECM Biosciences & $\mathrm{HM}-4381$ \\
\hline rabbit anti-TH & Abcam & ab112 \\
\hline rat anti-CD31 & BD Pharmingen & 553370 \\
\hline Lotus tetragonolobus lectin-Fluorescein & Vector Labs & FL-1321 \\
\hline mouse anti-ATP5A & Abcam & $a b 14748$ \\
\hline mouse anti- $\beta$-ACTIN & Abcam & $a b 8227$ \\
\hline mouse anti-CORE2 & Abcam & $\mathrm{ab8227}$ \\
\hline mouse anti-COX1 & Abcam & $a b 14705$ \\
\hline mouse anti-COX4i1 & Abcam & $a b 14744$ \\
\hline
\end{tabular}




\begin{tabular}{|l|l|l|}
\hline rabbit anti-COX4i2 & Abnova & $\begin{array}{l}\text { H00084701- } \\
\text { M01 }\end{array}$ \\
\hline mouse anti-COX5B & Santa Cruz & $\mathrm{sc-374417}$ \\
\hline mouse anti-ß-TUBULIN & Sigma Aldrich & C4585 \\
\hline rabbit anti-UQCRB & Abcam & ab122837 \\
\hline mouse anti-NDUFA9 & Abcam & ab14713 \\
\hline rabbit anti-NDUFB11 & Abcam & ab183716 \\
\hline rabbit anti-SDHA & Abcam & ab14715 \\
\hline mouse anti-cytochrome c & Santa Cruz & $\mathrm{sc}-13156$ \\
\hline & & \\
\hline
\end{tabular}




\section{References}

1. A. J. Chang, Acute oxygen sensing by the carotid body: from mitochondria to plasma membrane. J Appl Physiol (1985) 123, 1335-1343 (2017).

2. P. Ortega-Saenz, J. Lopez-Barneo, Physiology of the Carotid Body: From Molecules to Disease. Annu Rev Physiol 82, 127-149 (2020).

3. A. P. Holmes, C. J. Ray, A. M. Coney, P. Kumar, Is Carotid Body Physiological $\mathrm{O} 2$ Sensitivity Determined by a Unique Mitochondrial Phenotype? Front Physiol 9, 562 (2018).

4. A. Moreno-Dominguez et al., Acute $\mathrm{O} 2$ sensing through HIF2alpha-dependent expression of atypical cytochrome oxidase subunits in arterial chemoreceptors. Sci Signal 13, (2020).

5. M. C. Fernandez-Aguera et al., Oxygen Sensing by Arterial Chemoreceptors Depends on Mitochondrial Complex I Signaling. Cell Metab 22, 825-837 (2015).

6. C. A. Sinkler et al., Tissue- and Condition-Specific Isoforms of Mammalian Cytochrome c Oxidase Subunits: From Function to Human Disease. Oxid Med Cell Longev 2017, 1534056 (2017).

7. R. Iturriaga, Translating carotid body function into clinical medicine. J Physio/ 596, 30673077 (2018).

8. A. J. Chang, F. E. Ortega, J. Riegler, D. V. Madison, M. A. Krasnow, Oxygen regulation of breathing through an olfactory receptor activated by lactate. Nature 527, 240-244 (2015).

9. D. Macias et al., HIF-2alpha is essential for carotid body development and function. Elife 7, (2018).

10. A. Timon-Gomez, E. L. Bartley-Dier, F. Fontanesi, A. Barrientos, HIGD-Driven Regulation of Cytochrome c Oxidase Biogenesis and Function. Cells 9, (2020).

11. M. Uhlen et al., Proteomics. Tissue-based map of the human proteome. Science 347, 1260419 (2015).

12. H. J. An et al., The survival effect of mitochondrial Higd-1a is associated with suppression of cytochrome $\mathrm{C}$ release and prevention of caspase activation. Biochim Biophys Acta 1813, 2088-2098 (2011).

13. Y. Shen et al., A map of the cis-regulatory sequences in the mouse genome. Nature 488, 116-120 (2012).

14. P. Kumar, N. R. Prabhakar, Peripheral chemoreceptors: function and plasticity of the carotid body. Compr Physiol 2, 141-219 (2012).

15. T. Zhou, M. S. Chien, S. Kaleem, H. Matsunami, Single cell transcriptome analysis of mouse carotid body glomus cells. J Physiol 594, 4225-4251 (2016).

16. R. N. Suganthan, S. V. Pratap, E. H. Morita, A. Shunnosuke, Identification of a chimeric transcript formed by intergenic splicing of UbiE2 and Yghl1-4 in Mouse. Int Res J Biological Sci 3, 52-59 (2014).

17. B. Diaz-Castro, C. O. Pintado, P. Garcia-Flores, J. Lopez-Barneo, J. I. Piruat, Differential impairment of catecholaminergic cell maturation and survival by genetic mitochondrial complex II dysfunction. Mol Cell Biol 32, 3347-3357 (2012).

18. K. J. Buckler, TASK channels in arterial chemoreceptors and their role in oxygen and acid sensing. Pflugers Arch 467, 1013-1025 (2015).

19. Y. Lu, C. A. Whiteis, K. A. Sluka, M. W. Chapleau, F. M. Abboud, Responses of glomus cells to hypoxia and acidosis are uncoupled, reciprocal and linked to ASIC3 expression: selectivity of chemosensory transduction. J Physiol 591, 919-932 (2013).

20. Y. J. Peng et al., Olfactory receptor 78 participates in carotid body response to a wide range of low O2 levels but not severe hypoxia. J Neurophysiol 123, 1886-1895 (2020). 
21. Y. J. Peng et al., H2S mediates carotid body response to hypoxia but not anoxia. Respir Physiol Neurobiol 259, 75-85 (2019).

22. S. W. Perry, J. P. Norman, J. Barbieri, E. B. Brown, H. A. Gelbard, Mitochondrial membrane potential probes and the proton gradient: a practical usage guide. Biotechniques 50, 98-115 (2011).

23. A. Swiderska et al., Mitochondrial Succinate Metabolism and Reactive Oxygen Species Are Important but Not Essential for Eliciting Carotid Body and Ventilatory Responses to Hypoxia in the Rat. Antioxidants (Basel) 10, (2021).

24. A. Timon-Gomez, J. Garlich, R. A. Stuart, C. Ugalde, A. Barrientos, Distinct Roles of Mitochondrial HIGD1A and HIGD2A in Respiratory Complex and Supercomplex Biogenesis. Cell Rep 31, 107607 (2020).

25. A. Timon-Gomez et al., Mitochondrial cytochrome c oxidase biogenesis: Recent developments. Semin Cell Dev Biol 76, 163-178 (2018).

26. J. P. Shapleigh et al., Definition of the catalytic site of cytochrome c oxidase: specific ligands of heme a and the heme a3-CuB center. Proc Natl Acad Sci U S A 89, 47864790 (1992).

27. T. Hayashi et al., Higd1a is a positive regulator of cytochrome c oxidase. Proc Natl Acad Sci U S A 112, 1553-1558 (2015).

28. A. M. Hall, R. J. Unwin, N. Parker, M. R. Duchen, Multiphoton imaging reveals differences in mitochondrial function between nephron segments. J Am Soc Nephrol 20, 1293-1302 (2009).

29. S. Gong et al., Targeting Cre recombinase to specific neuron populations with bacterial artificial chromosome constructs. J Neurosci 27, 9817-9823 (2007).

30. H. A. Zariwala et al., A Cre-dependent GCaMP3 reporter mouse for neuronal imaging in vivo. J Neurosci 32, 3131-3141 (2012).

31. A. Roy et al., Anandamide modulates carotid sinus nerve afferent activity via TRPV1 receptors increasing responses to heat. J Appl Physiol (1985) 112, 212-224 (2012).

32. M. Bourens, A. Boulet, S. C. Leary, A. Barrientos, Human COX20 cooperates with SCO1 and SCO2 to mature COX2 and promote the assembly of cytochrome c oxidase. Hum Mol Genet 23, 2901-2913 (2014).

33. E. Fernandez-Vizarra et al., Isolation of mitochondria for biogenetical studies: An update. Mitochondrion 10, 253-262 (2010).

34. A. Timon-Gomez et al., Protocol for the Analysis of Yeast and Human Mitochondrial Respiratory Chain Complexes and Supercomplexes by Blue Native Electrophoresis. STAR Protoc 1, (2020).

35. A. Barrientos, F. Fontanesi, F. Diaz, Evaluation of the mitochondrial respiratory chain and oxidative phosphorylation system using polarography and spectrophotometric enzyme assays. Curr Protoc Hum Genet Chapter 19, Unit19 13 (2009).

36. M. J. Fagerlund et al., The human carotid body: expression of oxygen sensing and signaling genes of relevance for anesthesia. Anesthesiology 113, 1270-1279 (2010).

37. D. Otlyga, E. Tsvetkova, O. Junemann, S. Saveliev, Immunohistochemical Characteristics of the Human Carotid Body in the Antenatal and Postnatal Periods of Development. Int J Mol Sci 22, (2021).

38. D. Massberg et al., The activation of OR51E1 causes growth suppression of human prostate cancer cells. Oncotarget 7, 48231-48249 (2016). 
Fig. 1
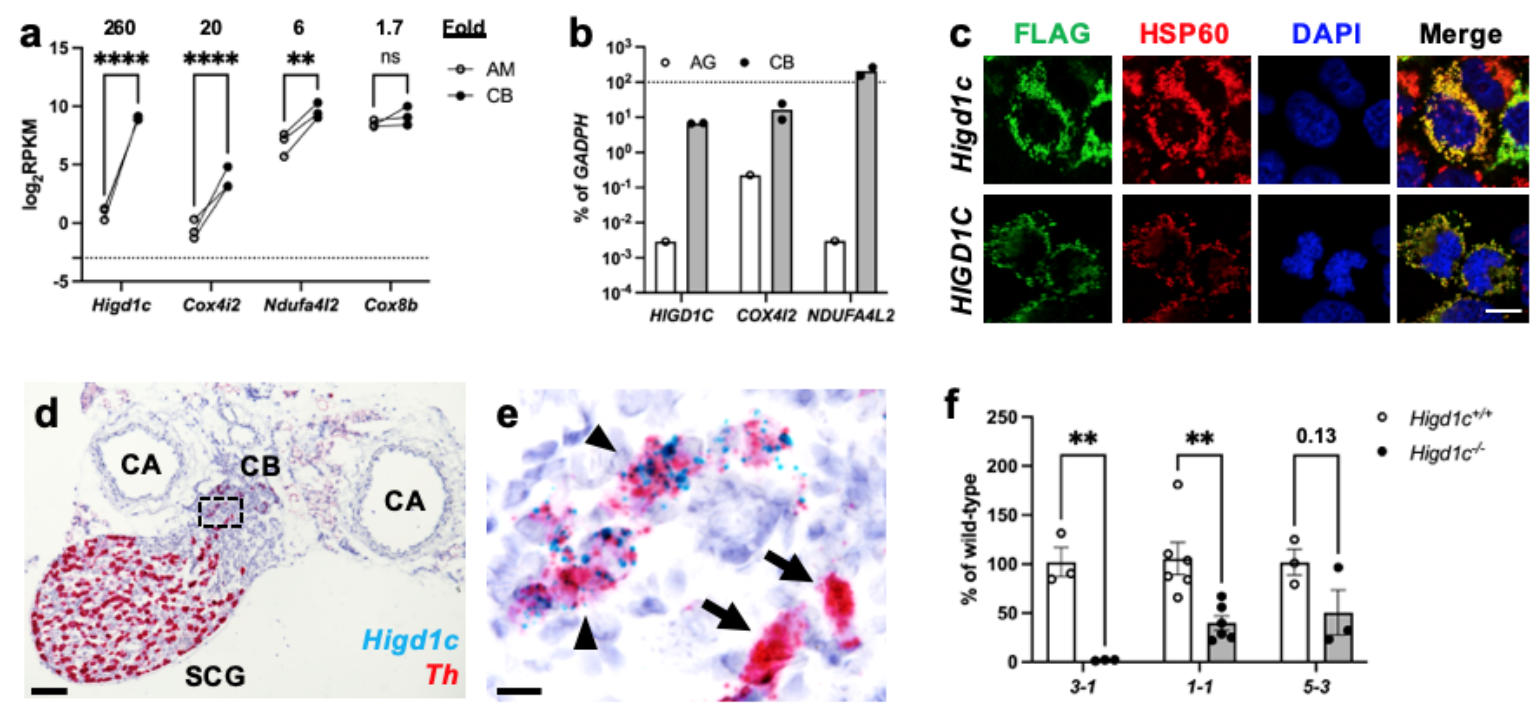

$\mathbf{e}$

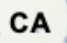

Higd1c

Th

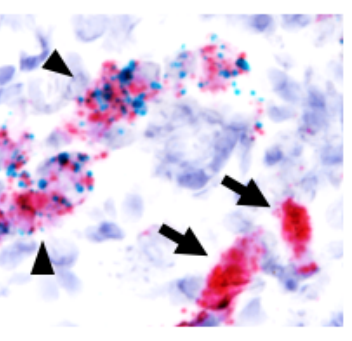

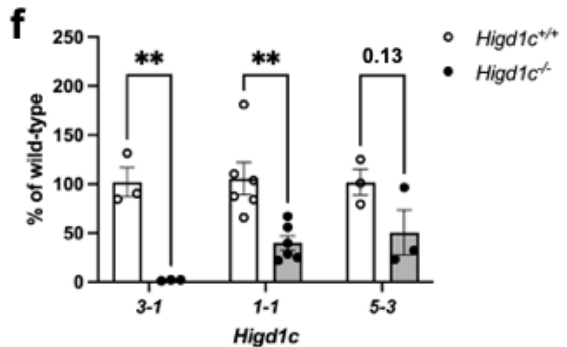

- $\mathrm{Higd}_{1} \mathrm{c}^{+/ t}$

- Higd1 $c^{\%}$
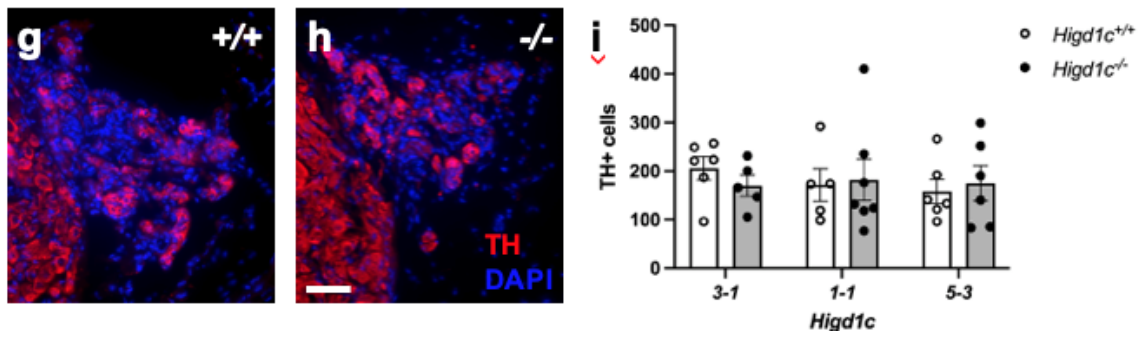
Fig. 2

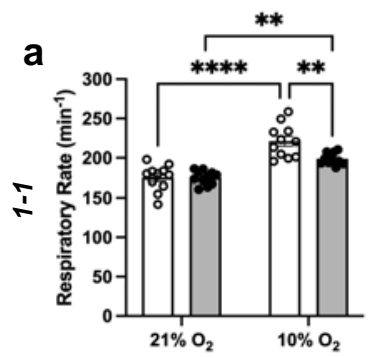

b
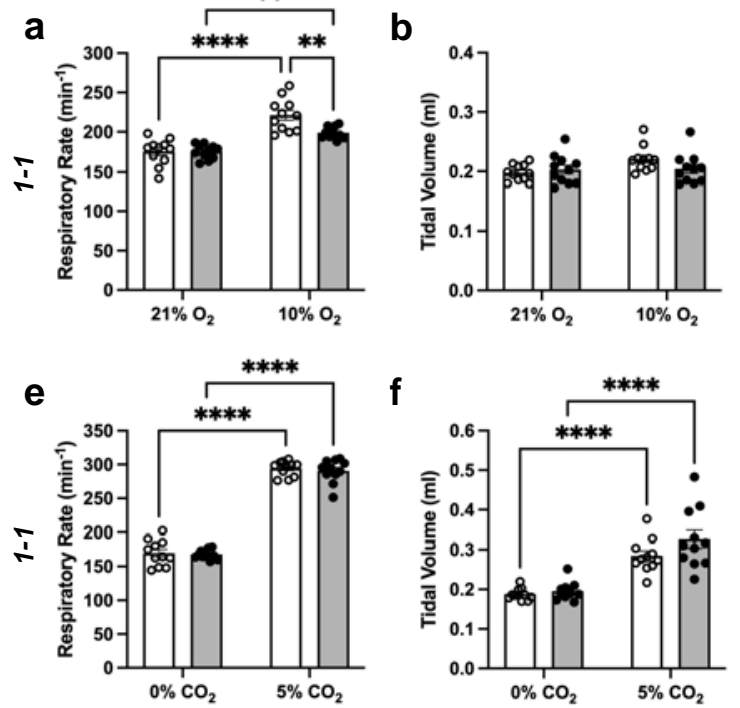

f

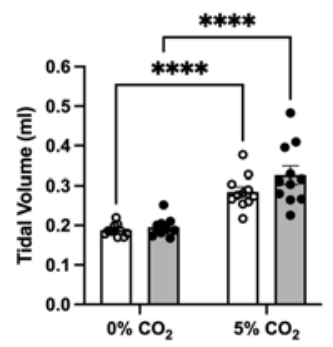

C
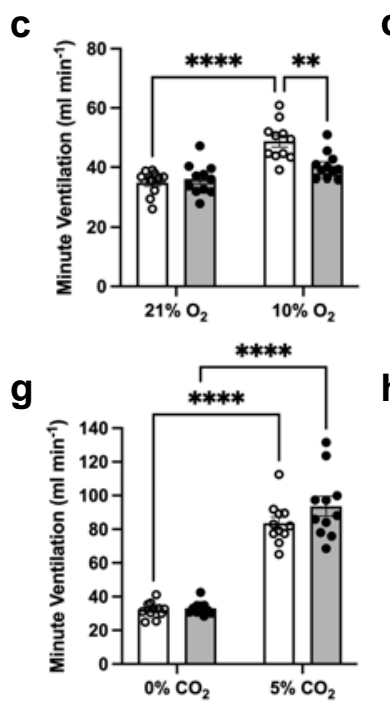

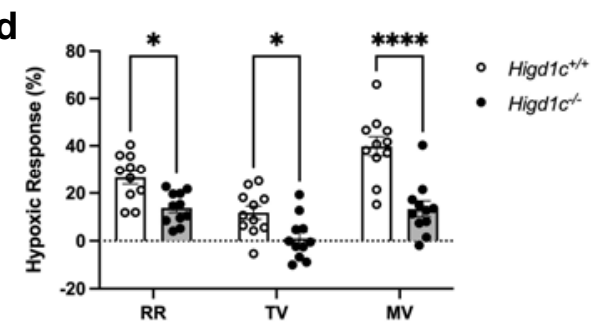

h

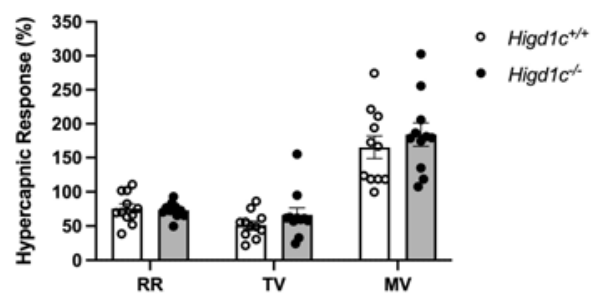


bioRxiv preprint dol: https://doi.org/10.1101/2021.10.04.463079; this version posted October 5,2021 . The copyright holder for this preprint (which was not certified by peer review) is the author/funder. All rights reserved. No reuse allowed without permission.

Fig. 3
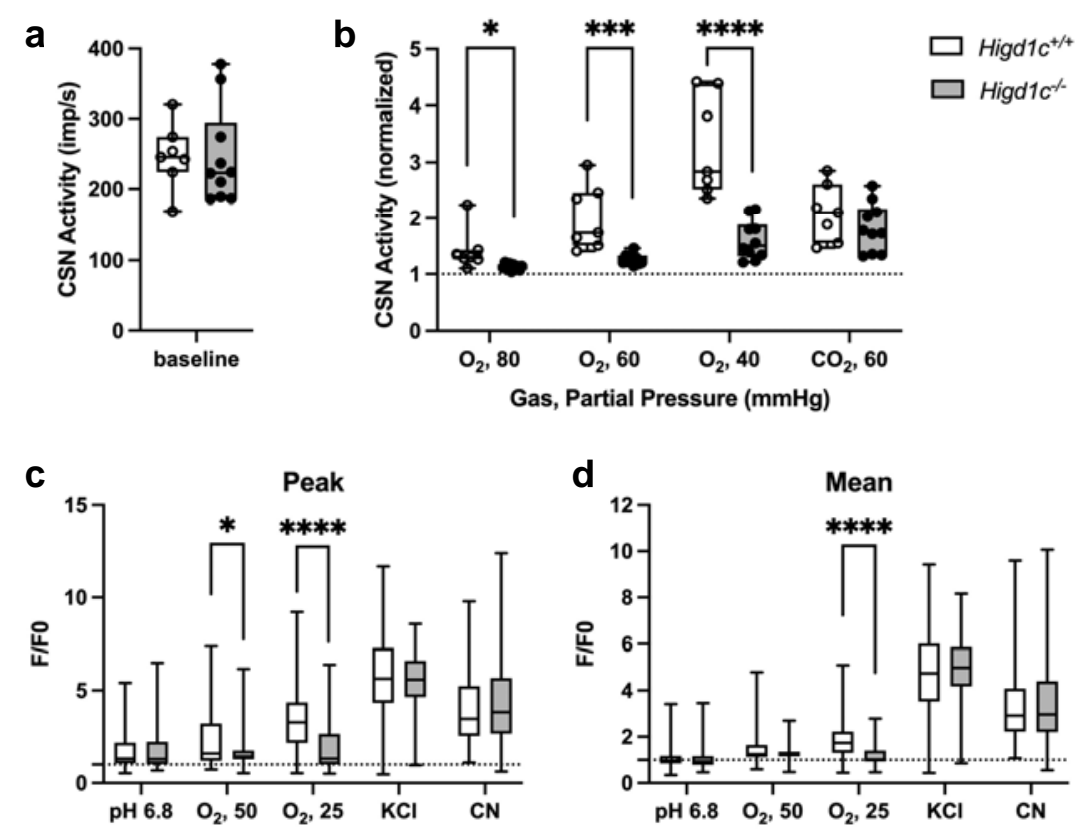
bioRxiv preprint dol: https://doi.org/10.1101/2021.10.04.463079; this version posted October 5,2021 . The copyright holder for this preprint (which was not certified by peer review) is the author/funder. All rights reserved. No reuse allowed without permission.

Fig. 4
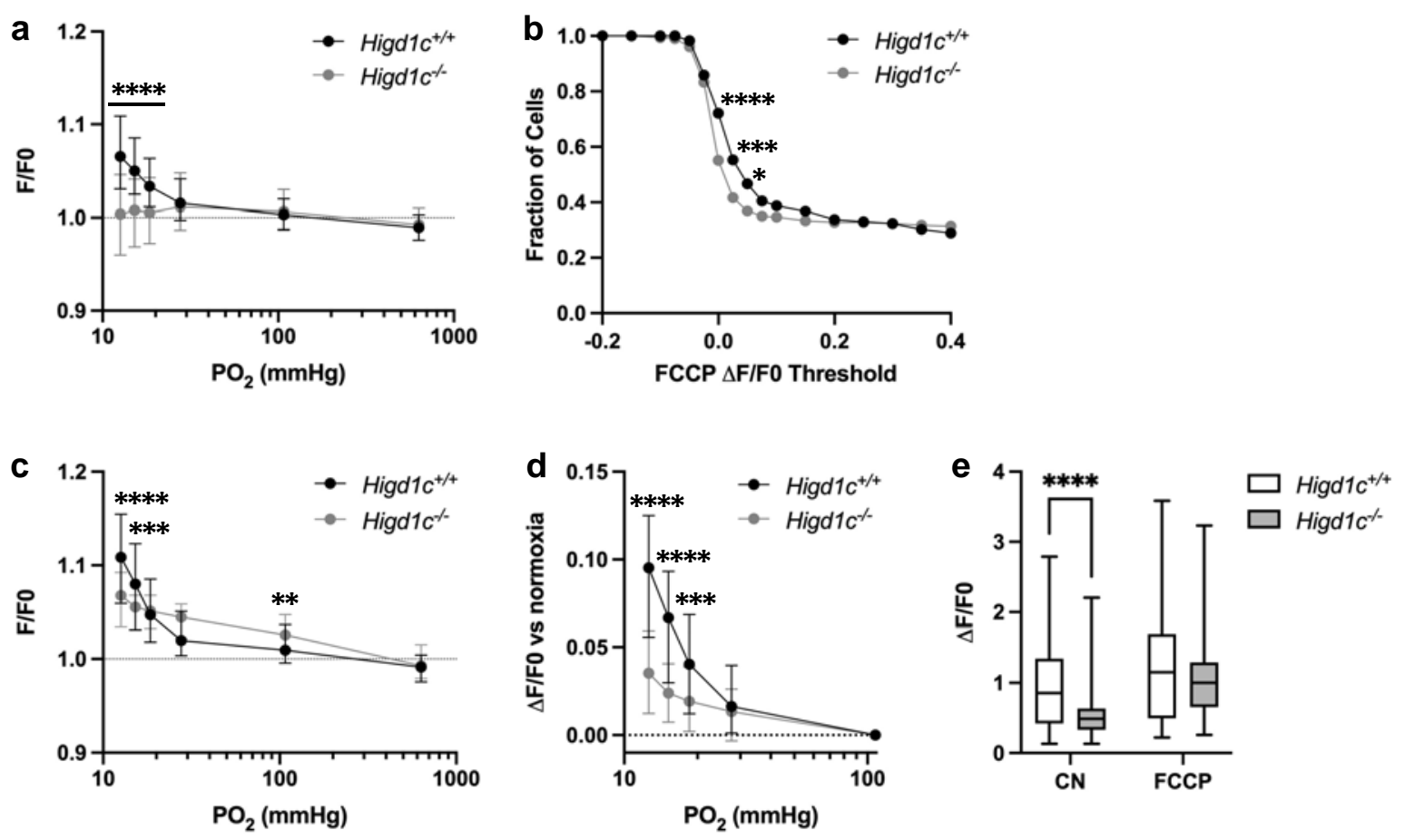
Fig. 5

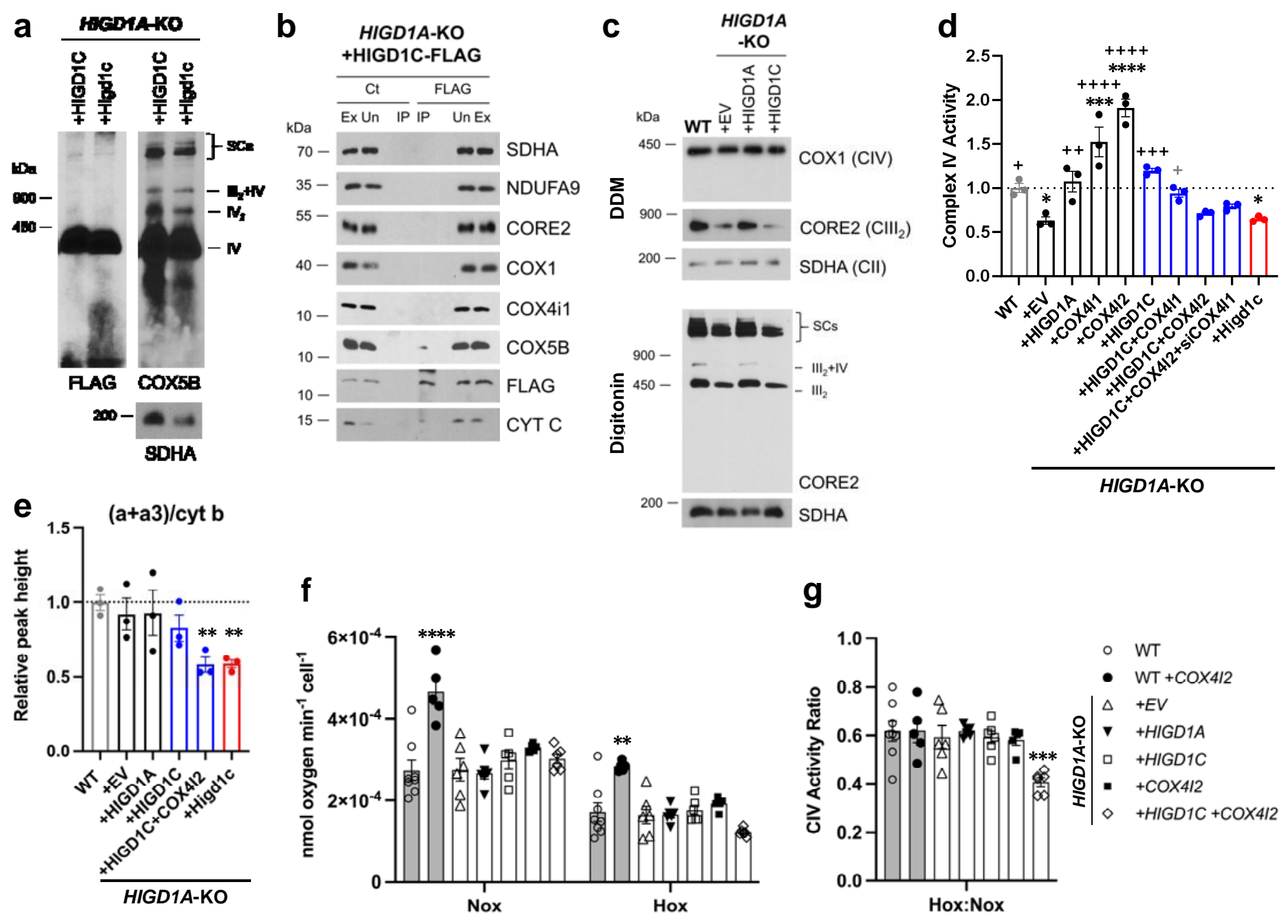


a

$1 \mathrm{~kb}$
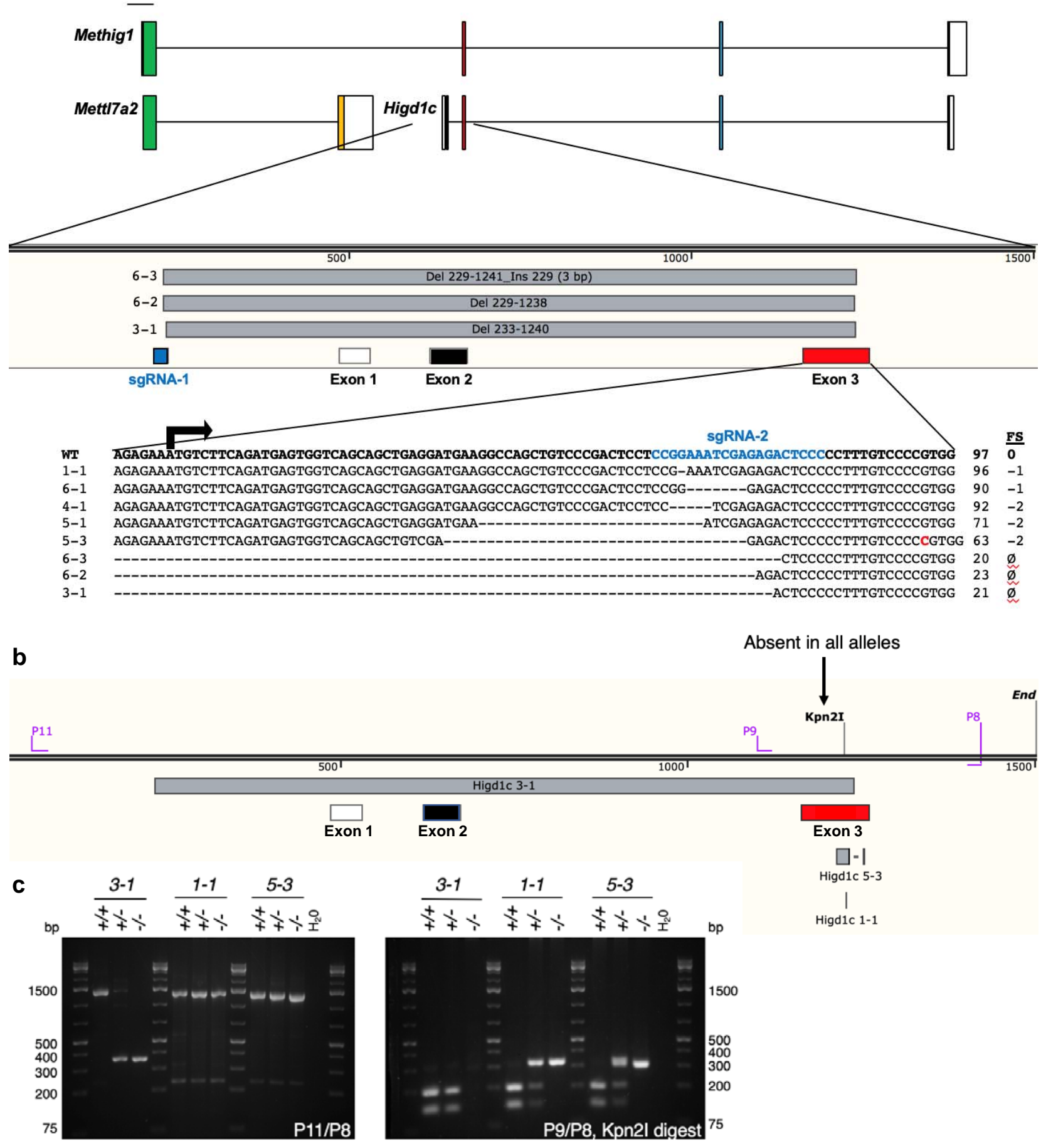

d

\begin{tabular}{|c|c|c|}
\hline Allele & Mutation(s) & Change in amino acid sequence (full length=96 aa) \\
\hline 1-1 & Del $1229(-1 \mathrm{bp})$ & starting at 21 , early stop at 45 \\
\hline $6-1$ & Del $1231-1237$ (-7 bp) & starting at 21 , early stop at 43 \\
\hline $4-1$ & Del_1229-1233 (-5 bp) & starting at 20 , early stop at 80 \\
\hline $5-1$ & Del_1204-1229 (-26 bp) & starting at 12 , early stop at 73 \\
\hline $5-3$ & Del_1216-1233 (-18 bp), Ins_1254_C (+1 bp) & deletion of $16-21$, change starting at 30 , early stop at 76 \\
\hline $6-3$ & Del 229-1238 (-1010 bp), Ins 229 CCT (+3 bp) & no protein or truncated protein missing $\mathrm{N}$-terminus \\
\hline $6-2$ & Del_229-1238(-1010 bp) & no protein or truncated protein missing $\mathrm{N}$-terminus \\
\hline 3-1 & Del $233-1240(-1008 \mathrm{bp})$ & no protein or truncated protein missing $\mathrm{N}$-terminus \\
\hline
\end{tabular}


Fig. S2
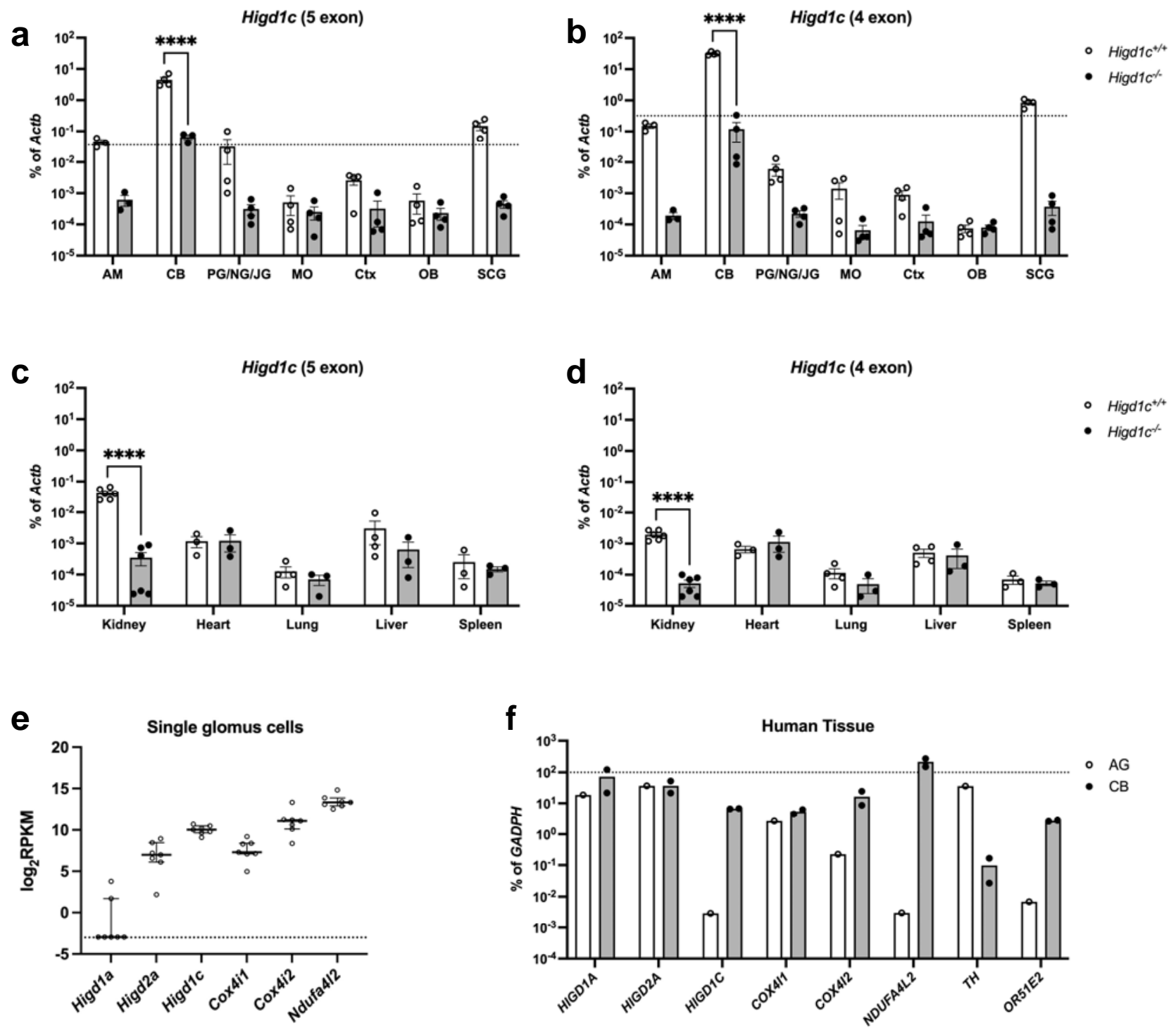
bioRxiv preprint doi: https://doi.org/10.1101/2021.10.04.463079; this version posted October 5, 2021. The copyright holder for this preprint (which was not certified by peer review) is the author/funder. All rights reserved. No reuse allowed without permission.

Fig. S3
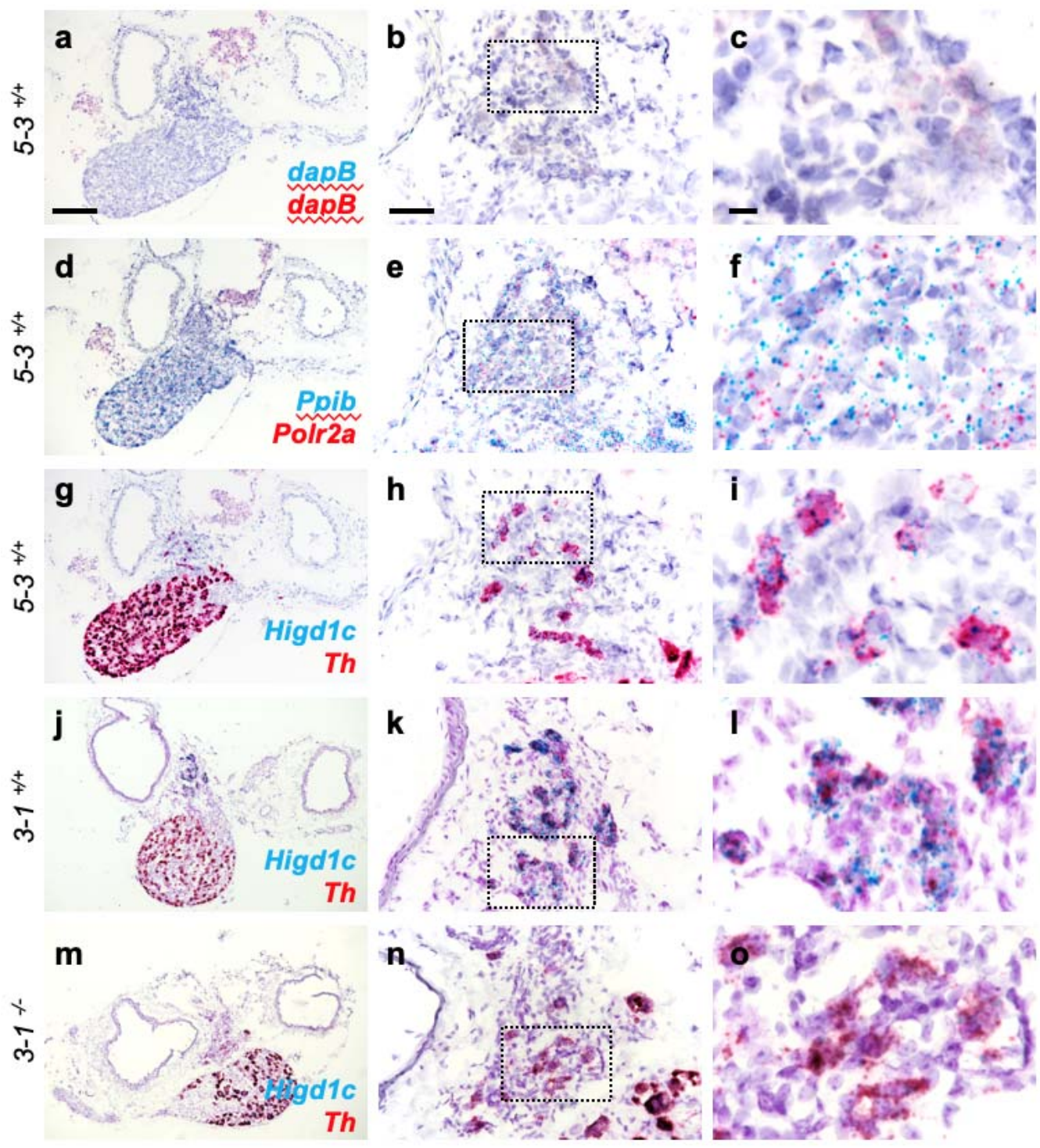
bioRxiv preprint doi: https://doi.org/10.1101/2021.10.04.463079; this version posted October 5, 2021. The copyright holder for this preprint (which was not certified by peer review) is the author/funder. All rights reserved. No reuse allowed without permission.

Fig. S4
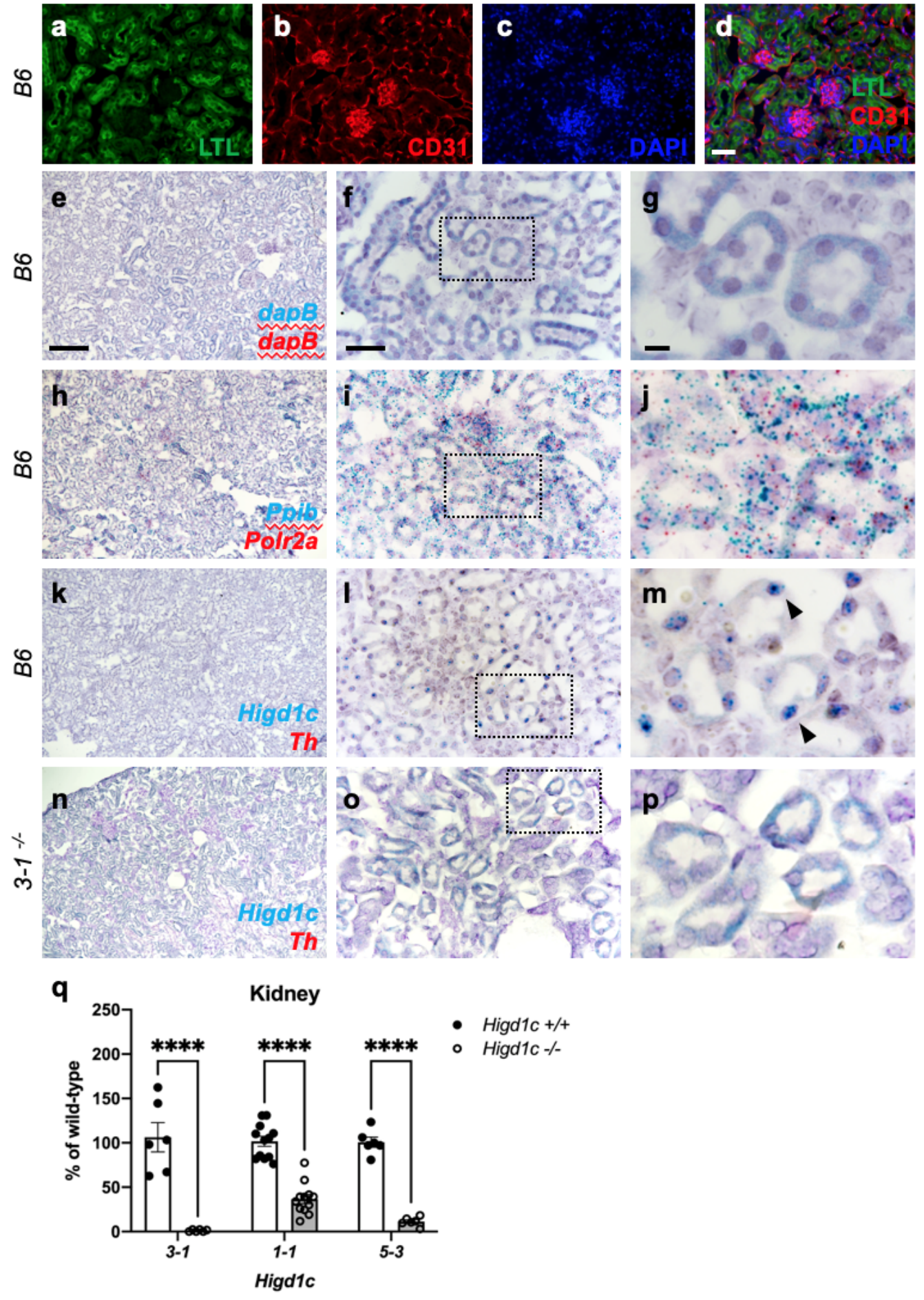

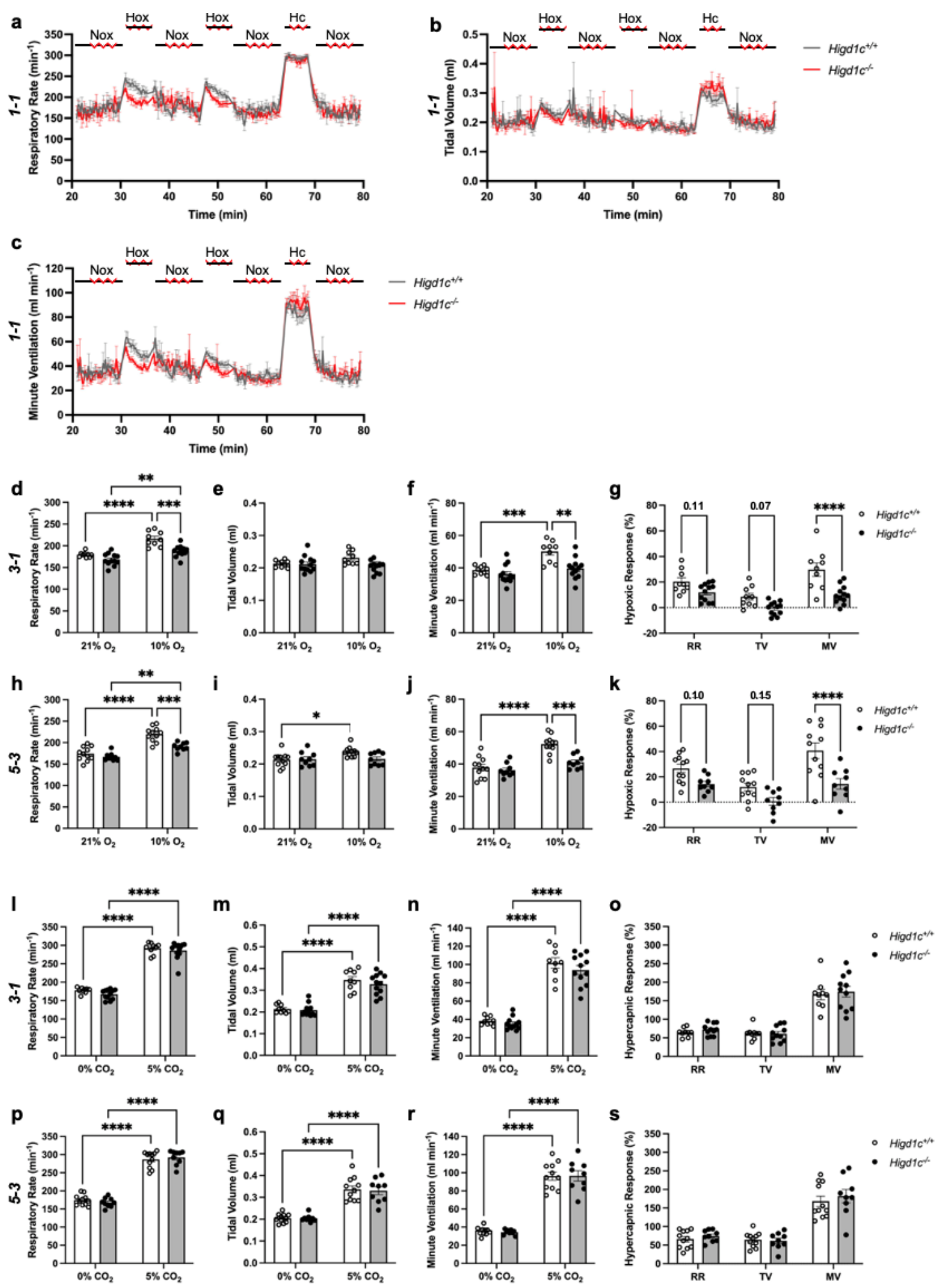
Fig. S6

a

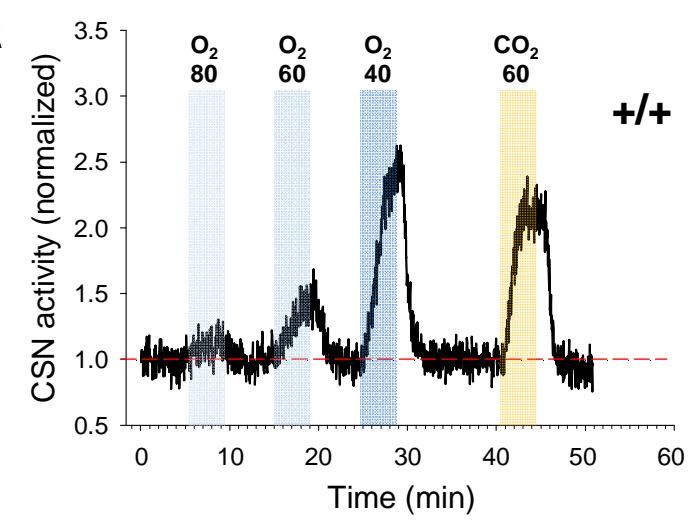

C

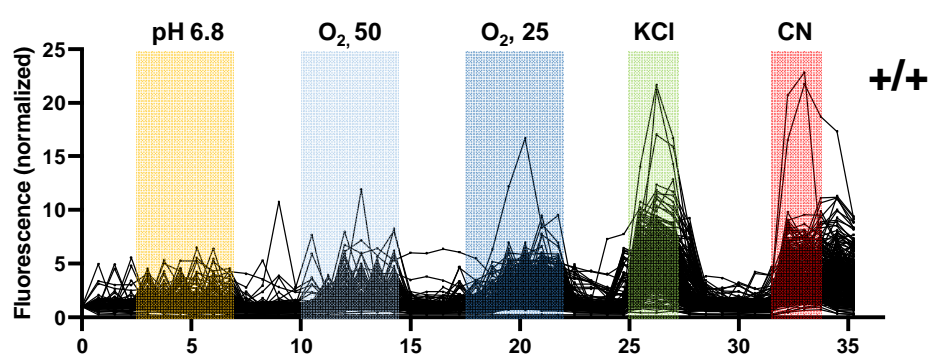

d

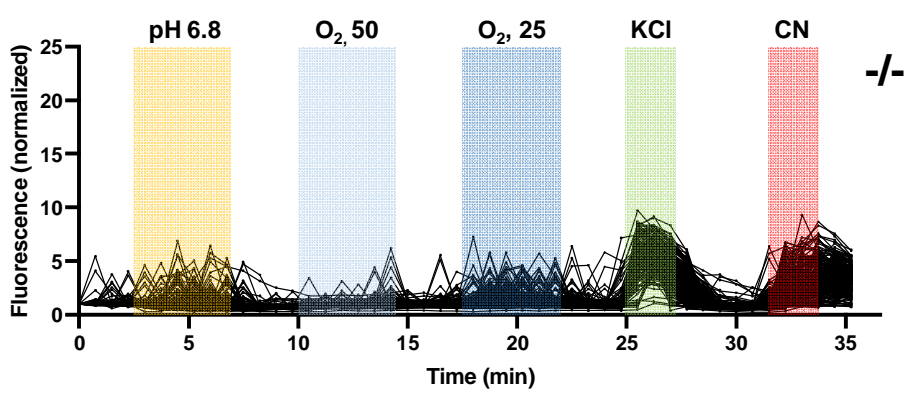

g

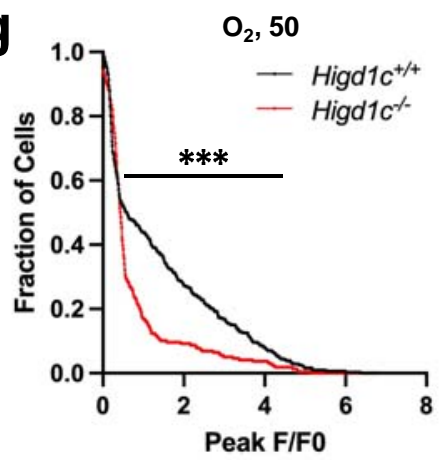

h

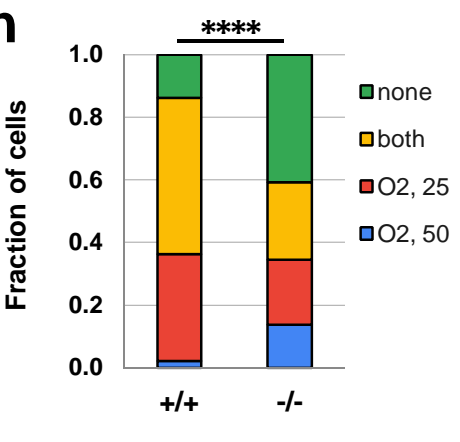

b
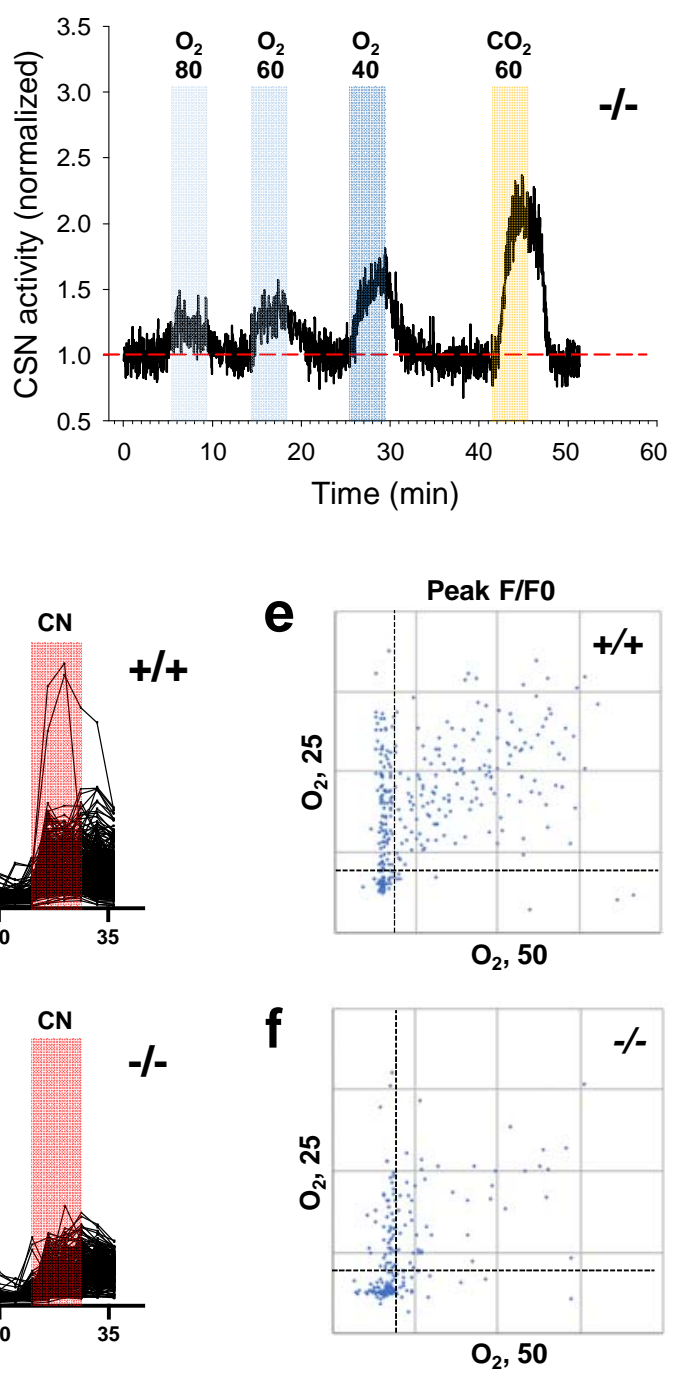


\section{Fig. S7}

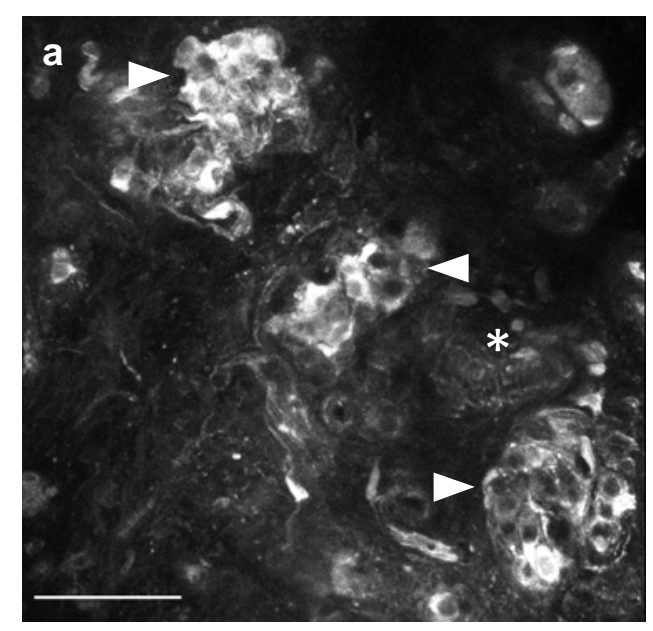

All cells
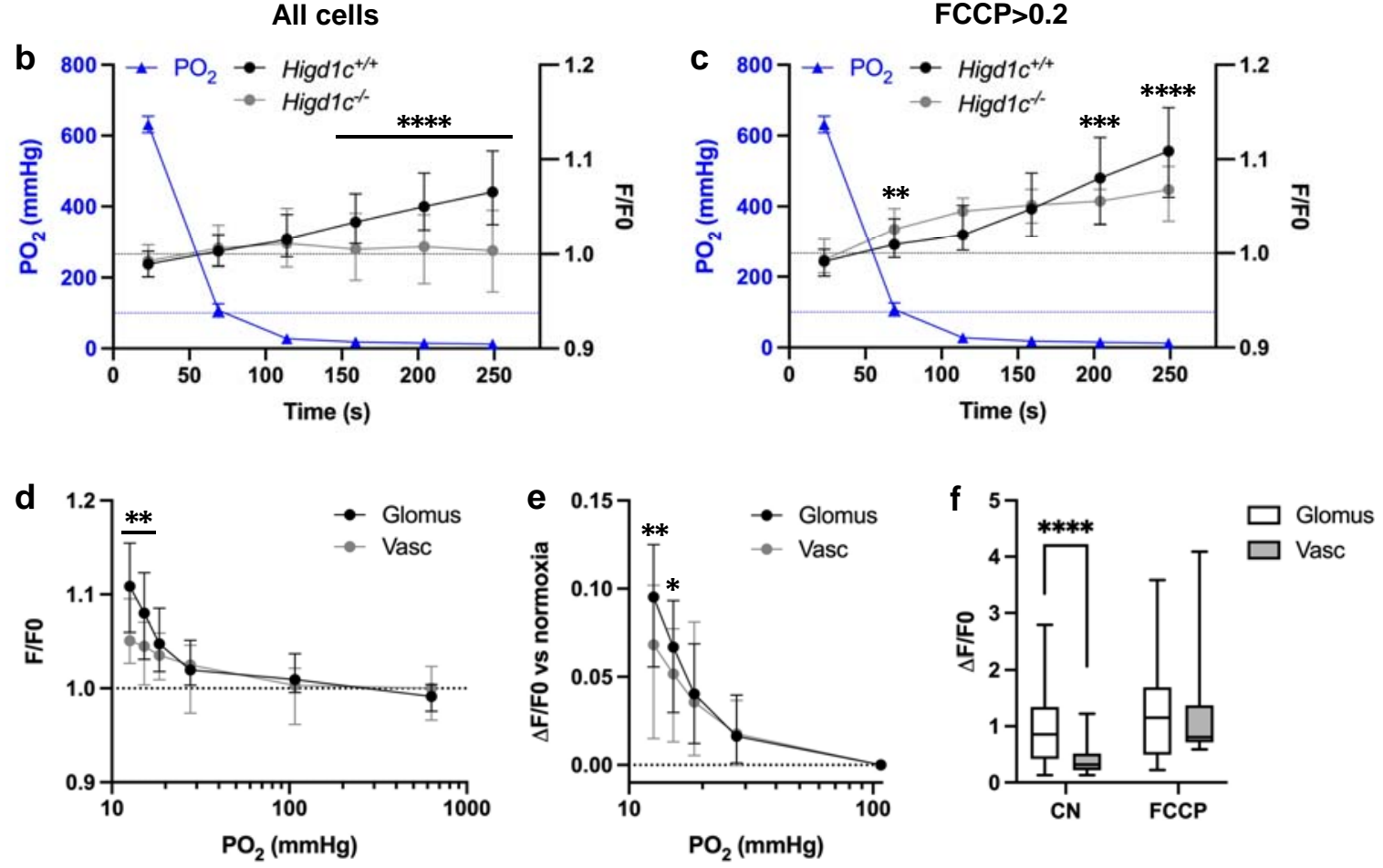
a

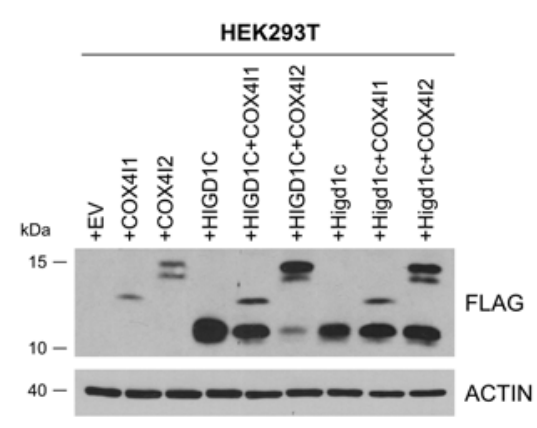

b

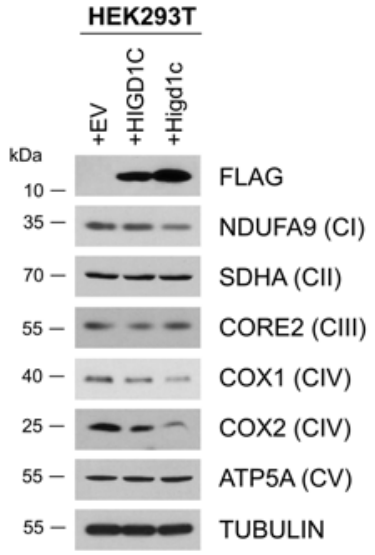

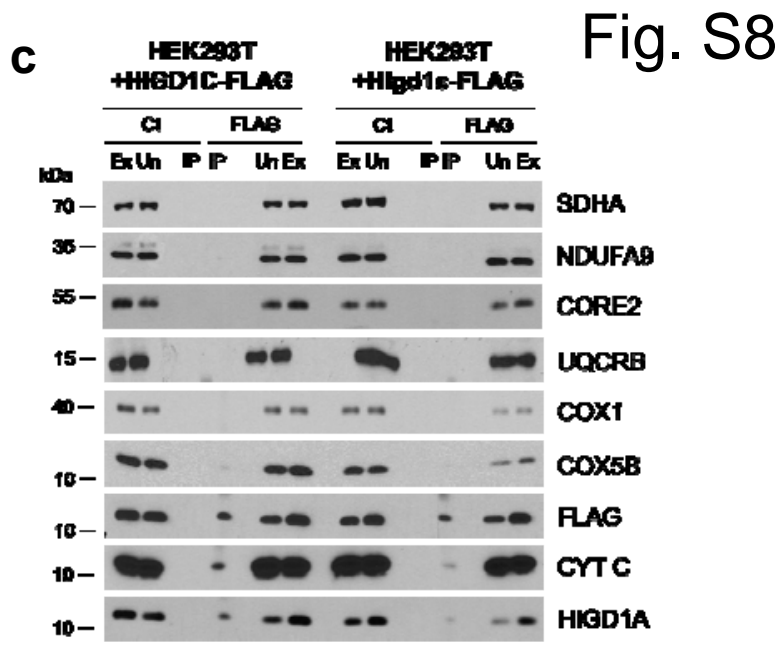

Digitonin

HEK293T HEK293T HEK293T HEK293T HEK293T HEK293T HEK293T

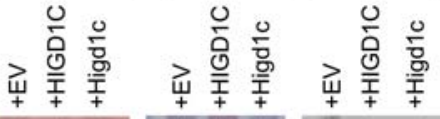

岸旁 $\frac{0}{\frac{0}{5}}$

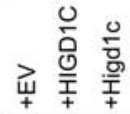

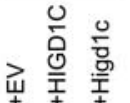

岸旁 $\frac{0}{\frac{0}{5}}$

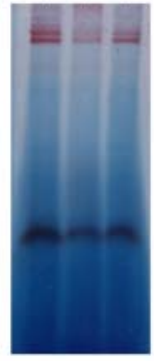

CI-IGA

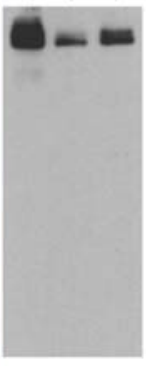

NDUFB11

(Cl)

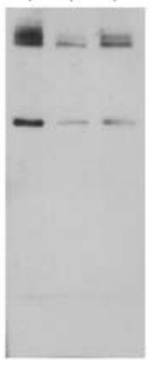

CORE2

(CIII)

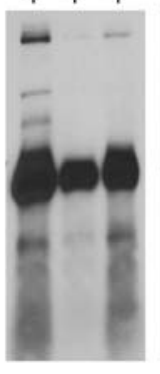

COX5B

(CIV)

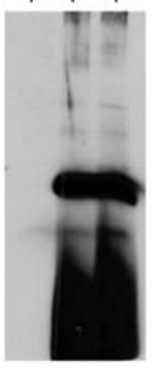

FLAG

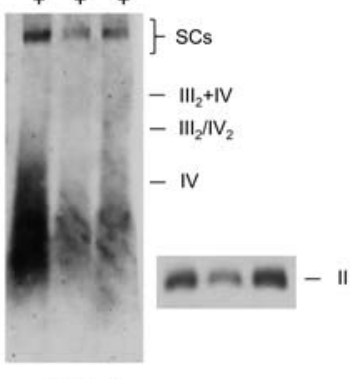

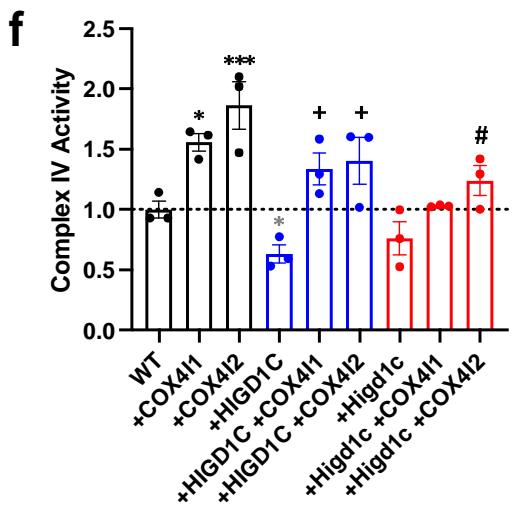

g

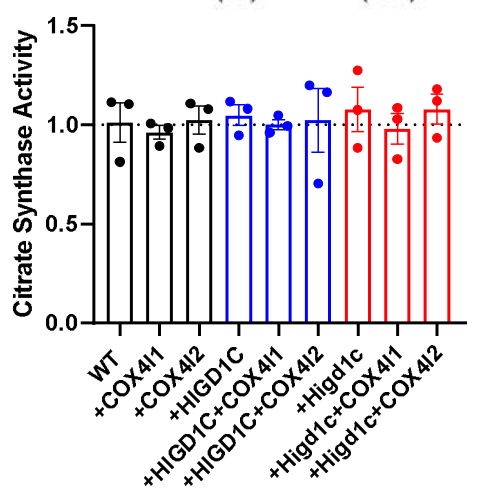

h

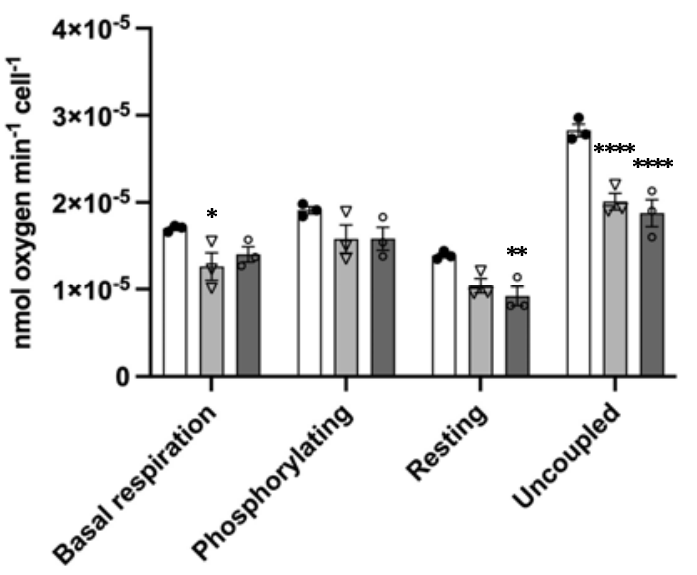

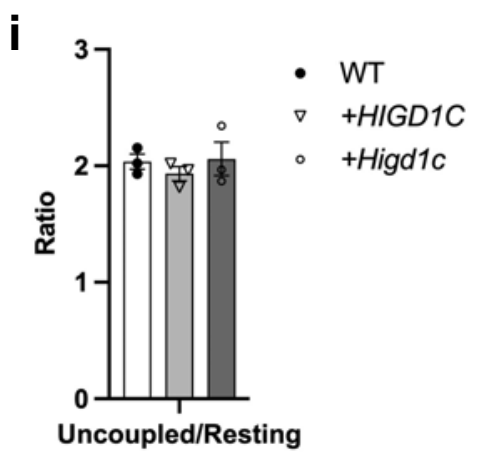


Fig. S9

a

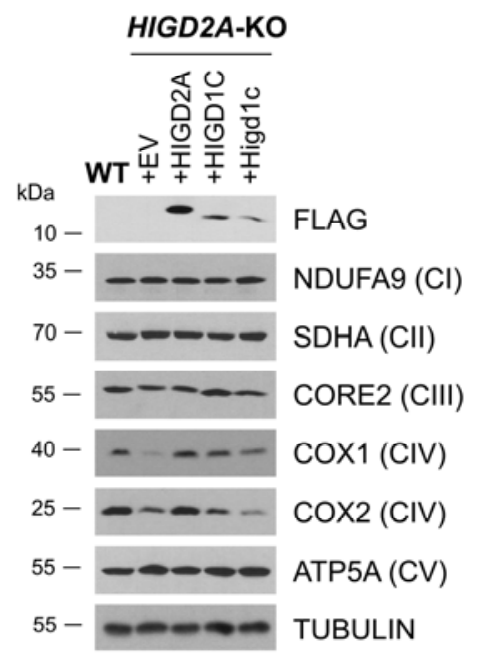

b HIGD2A-KO
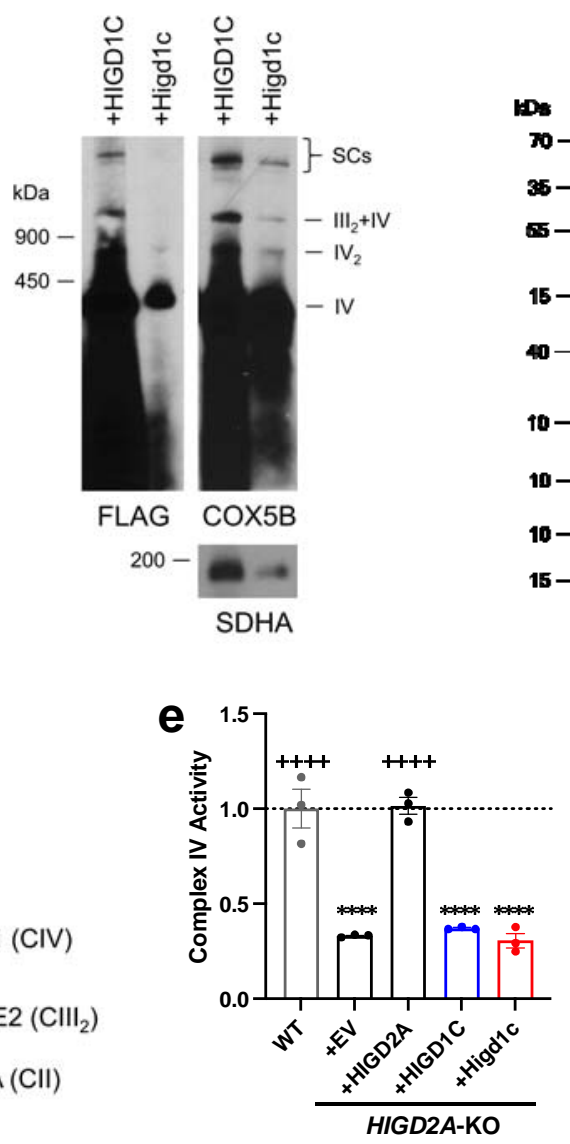

c

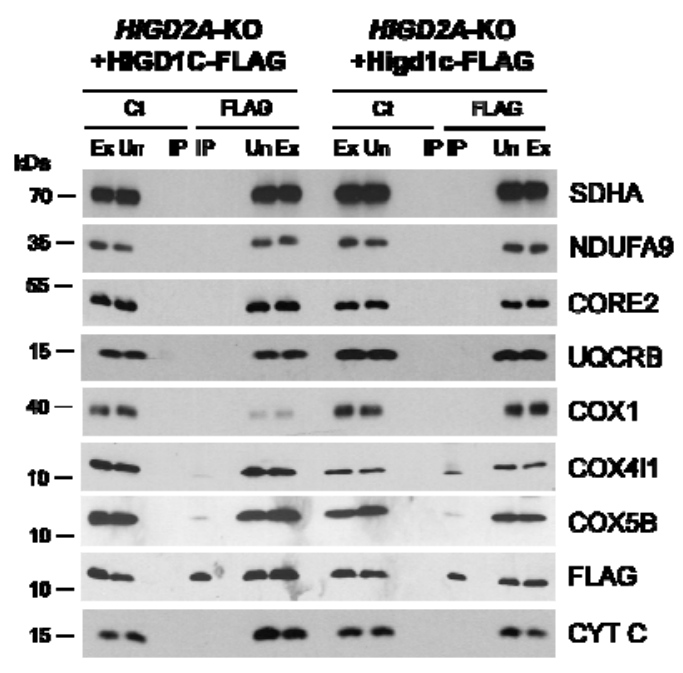

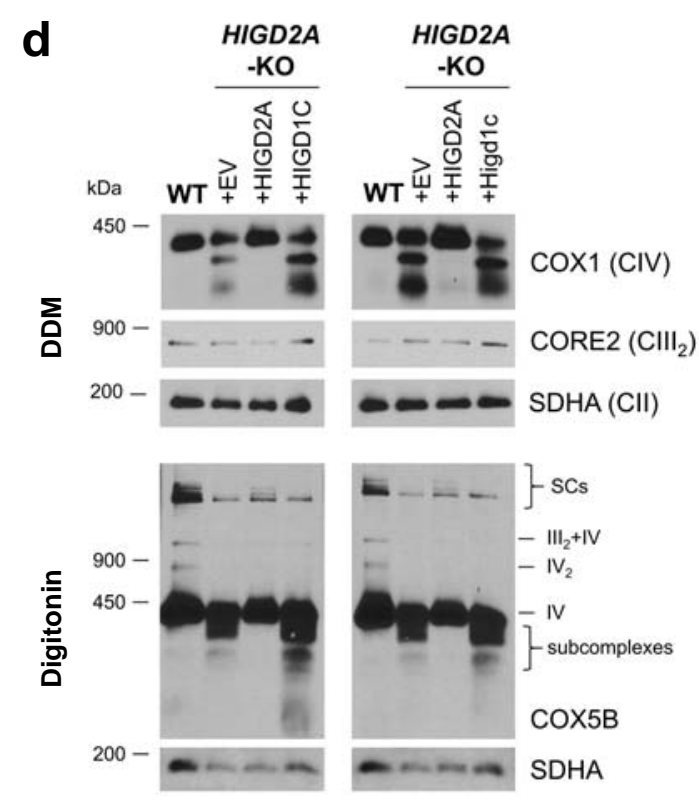

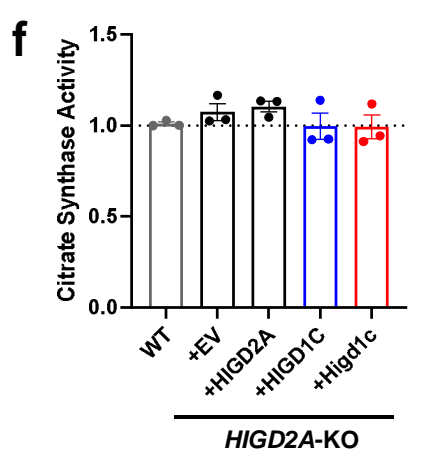


a

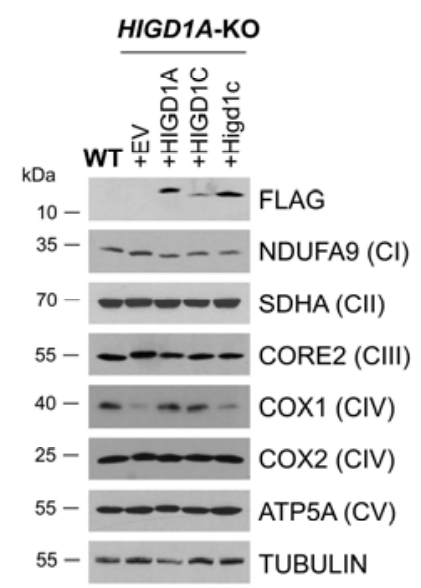

d

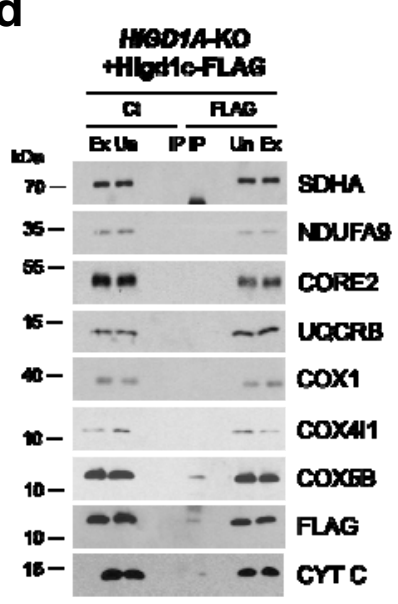

b

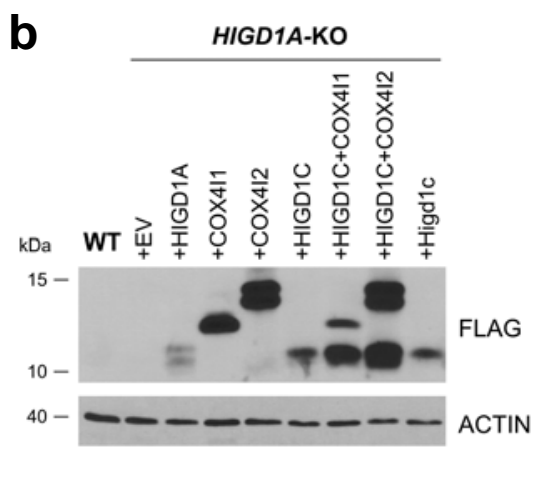

e

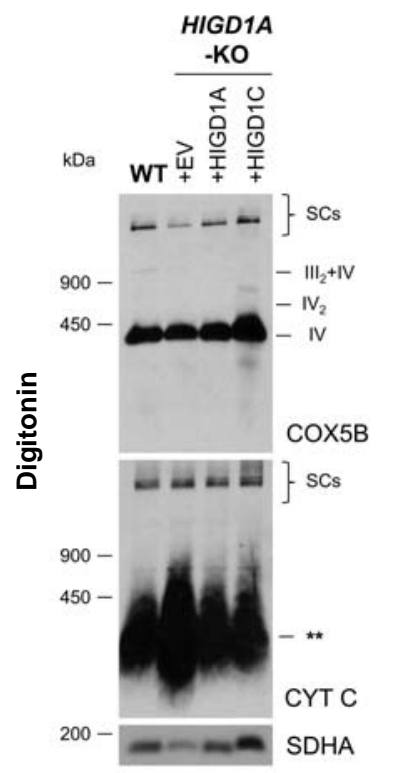

\section{f}

C HGDAKO

Fig. S10
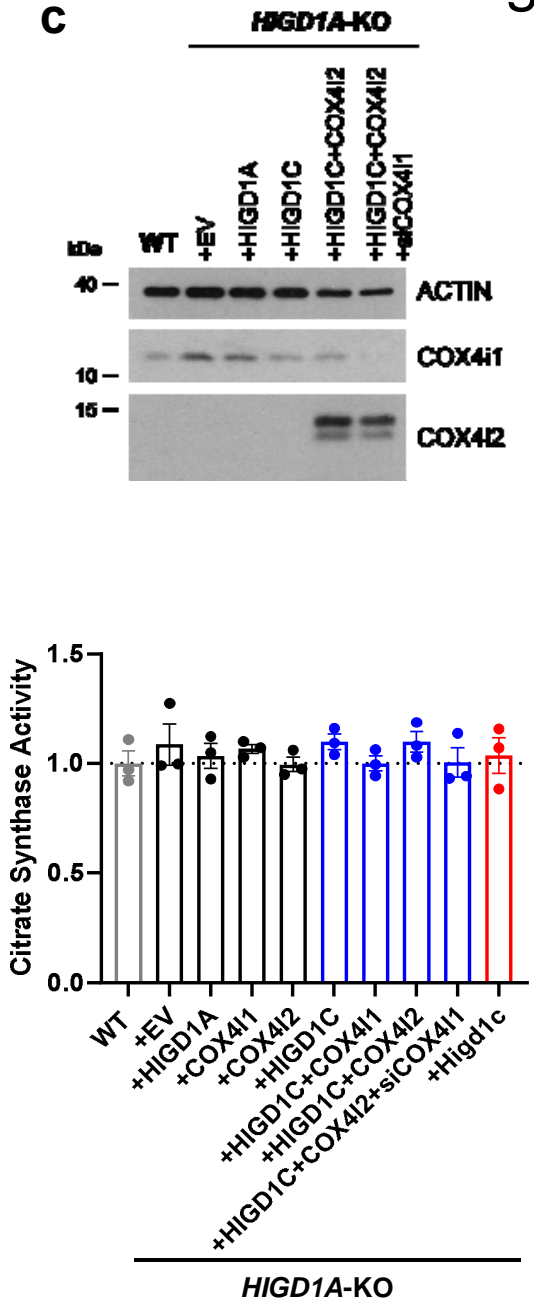

\section{g}
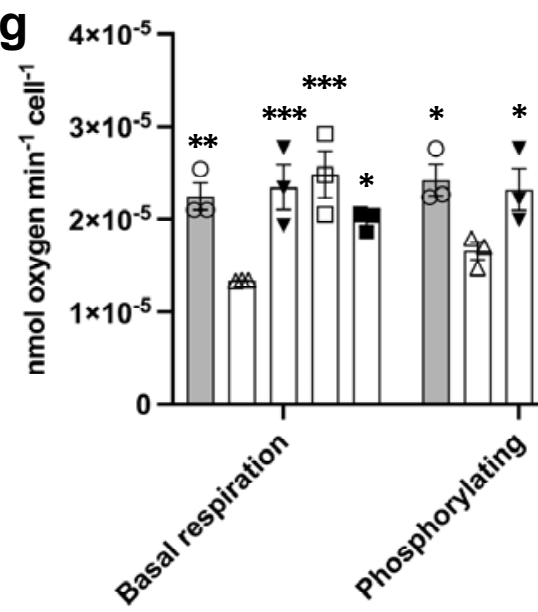
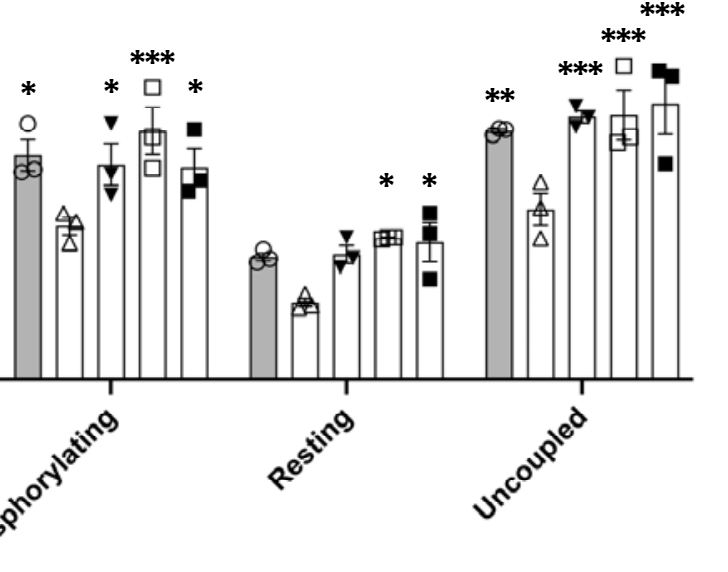

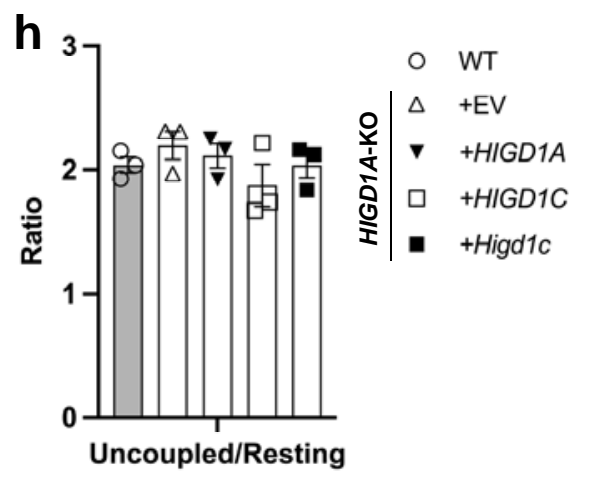

i

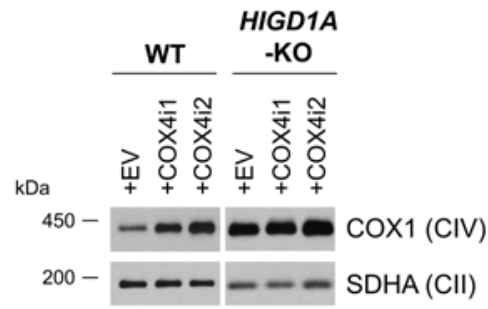



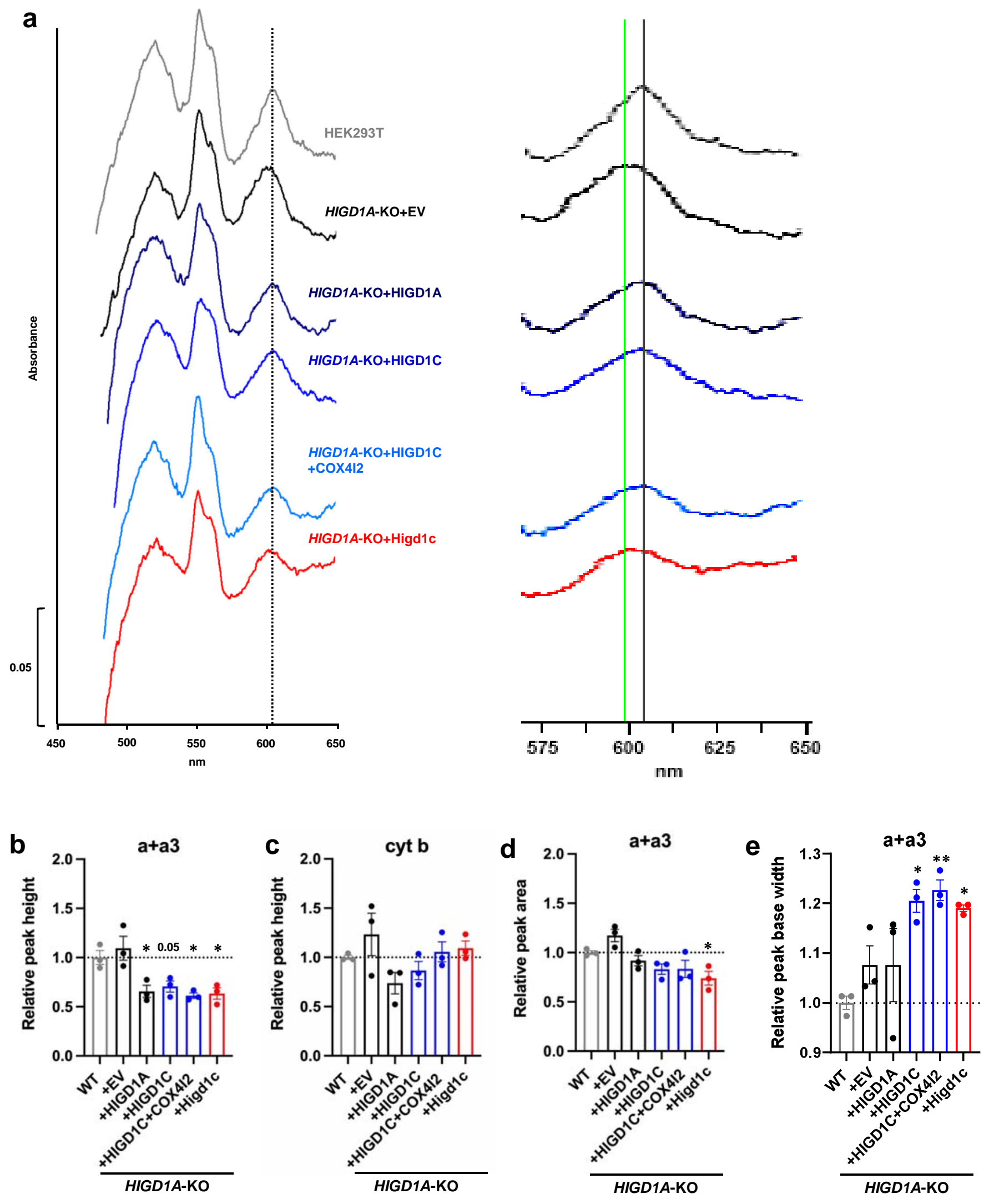